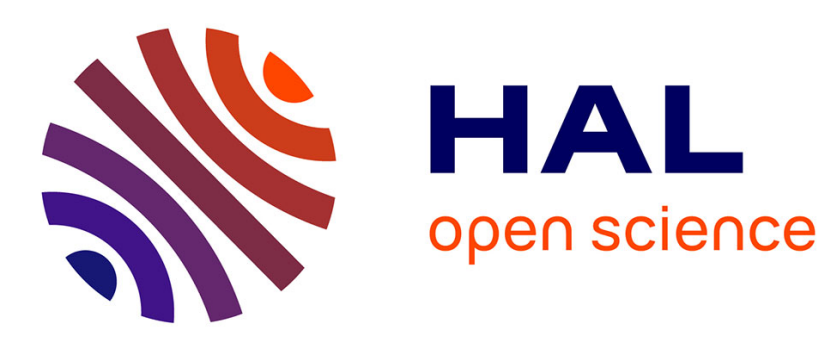

\title{
L'artillerie légère nousantarienne. A propos de six canons conservés dans des collections portugaises
}

Pierre-Yves Manguin

\section{To cite this version:}

Pierre-Yves Manguin. L'artillerie légère nousantarienne. A propos de six canons conservés dans des collections portugaises. Arts Asiatiques, 1976, 32 (1), pp.233 - 268. 10.3406/arasi.1976.1103. halshs-02509117

\section{HAL Id: halshs-02509117 https://shs.hal.science/halshs-02509117}

Submitted on 16 Mar 2020

HAL is a multi-disciplinary open access archive for the deposit and dissemination of scientific research documents, whether they are published or not. The documents may come from teaching and research institutions in France or abroad, or from public or private research centers.
L'archive ouverte pluridisciplinaire HAL, est destinée au dépôt et à la diffusion de documents scientifiques de niveau recherche, publiés ou non, émanant des établissements d'enseignement et de recherche français ou étrangers, des laboratoires publics ou privés. 


\section{L'artillerie légère nousantarienne. A propos de six canons} conservés dans des collections portugaises

Pierre-Yves Manguin

\section{Citer ce document / Cite this document :}

Manguin Pierre-Yves. L'artillerie légère nousantarienne. A propos de six canons conservés dans des collections portugaises. In: Arts asiatiques, tome 32, 1976. pp. 233-268;

doi : https://doi.org/10.3406/arasi.1976.1103

https://www.persee.fr/doc/arasi_0004-3958_1976_num_32_1_1103

Fichier pdf généré le 20/04/2018 


\section{L'ARTILLRIE IÉGÈRE NOLSANTARIENNE A PROPOS DE SIX CANONS CONSERVÉS DANS DES COLLECTIONS PORTUGAISES ${ }^{(1)}$}

\section{par Pierre-Yves MANGUIN}

Lors d'une visite à Macao en 1973, j'eus la surprise de découvrir dans une salle du Musée Luís de Camões un très beau spécimen de canon (pièce $F$ ). Sa provenance n'y était pas connue, mais les motifs dont il est orné ne peuvent être que de facture javanaise et un examen plus attentif révéla bientôt deux inscriptions javanaises, outre quelques sigles curopéens.

En 1974, en me rendant au Musée Militaire de Lisbonne pour examiner la très grosse bouche à feu indienne, dite "de Malacca», dont la légende veut qu'elle ait été prise à la chute de la ville en 1511, je pus faire d'autres découvertes. Dans les salles du sous-sol, mon attention fut attirée par une petite pièce d'artillerie d'une très belle finition, dont les motifs décoratifs trahissaient une origine nousantarienne certaine (pièce D). J'en trouvais bientôt quatre autres, de trois types différents, réparties au hasard parmi les pièces européennes. Deux d'entre elles seulement portaient une étiquette qui leur attribuait une origine philippine (pièces G et E) (2). Des recherches effectuécs aussitôt par le conseiller technique du Muséc révèlèrent en fait que ces pièces n'avaient aucune " histoire " et que rien ne permettait de préciser quand ni comment elles étaient parvenues dans les collections. Les datations portées

(1) Il me faut exprimer ici ma reconnaissance à ceux qui m'ont autorisé à photographier et à examiner en détail ces six pièces : M. Luís Gonzaga Gomes, à l'énergie duquel l'histoire et la vie culturelle de Macao doivent tant; et, à Lisbonne, M. João de Loureiro de Figueiredo, conseiller technique du Musée Militaire.

(2) Voici les textes de ces étiquettes: (Pièce G) : "Lantaca. Bronze. xvur ${ }^{\mathrm{e}}$ ou xrx ${ }^{\mathrm{e}}$ siècle. Calibre $2,1 \mathrm{~cm}$. Tire une balle de plomb de 57,36 g. Fourche d'appui. C'est la plus petite bouche à feu de ce Musée Militaire. Elle faisail feu appuyée sur une fourche, sur les lisses des navires, à l'occasion des abordages. "(Pièce E) : "Lantaca. Pièce de marine en bronze. Calibre $4 \mathrm{~cm}$. Originaire des Iles Philippines. Les lantacas étaient utilisées en général par les pirates des mers extrême-nrientales. On peut penser pour cette raison que cette pièce nous est venue de Macao. Fin xvie ou début xvil 'siècle. 
sur les étiquettes ne reposent en fait que sur un examen superficiel des canons : celle, tardive ( $\mathrm{xIX}^{\mathrm{e}}$ ou $\mathrm{xx}^{\mathrm{e}}$ siècles), de la pièce $\mathrm{C}$, véritable bijou, lui était attribuée $\mathrm{du}$ fait de son excellente finition, alors que la pièce $\mathrm{E}$, moins décorée et de facture plus grossière, se voyait arbitrairement attribuer une date bien antéricure $\left(\mathrm{XVI}^{\mathrm{e}}\right.$ ou Xvir ${ }^{\mathrm{e}}$ siècles).

Il y a moins d'un siècle, la fonte de canons comparables était encore bien attestéc dans certaines régions de l'Archipel : à Brunei, Shariffuddin affirme qu'ils étaient encore fondus régulièrement à la fin du $\mathrm{xIx}^{\mathrm{e}}$ siècle; et on sait par ailleurs qu'à Mindanao les Américains durent se battre en 1904 contre des Moros armés de «lantakas " (1).

Mais c'est en fait dès le Xvi ${ }^{\mathrm{e}}$ siècle, à l'arrivée des Ibériques en Asic du sud-est, que l'usage d'une abondante artillerie légère est attestée dans les diverses sources disponibles. Les documents portugais et espagnols font alors en effet très souvent mention de pièces embarquées sur les navires nousantariens, ou bien défendant des fortifications. Je me contenterai ici d'en extraire quelques passages caractéristiques, qui traduisent bien l'usage généralisé de ces canons sur l'ensemble de l'Archipel (2).

Les habitants de Malaka, lors de la prise de la ville, "possèdent beaucoup de cuivre et d'étain [et ils sont] aussi bons fondeurs que les Allemands " (3). En 1513, la flotte de Patih Yunus de Japara, venue attaquer Malaka, portait «beaucoup d'artillerie fabriquée à Java, car [les Javanais] sont d'excellents fondeurs" (4). Andrés Urdancta, espagnol fait prisonnier aux Moluques et ramené à Malaka en 1535 via Panarukan, confirme ces capacités : "[Les Javanais] possèdent bcaucoup d'artillerie en bronze, qu'ils fondent eux-mêmes » (5). A l'extrême-est de l'Archipel, l'usage de l'artillerie embarquée est tout aussi courant : Gabriel Rebello (6) décrit en 1561 la plus grande des embarcations de Ternate (le juanga) qui aurait porté

(1) P. M. Shariffuddin, "Brunei Cannon ", Brunei Museum Journal, I/1, 1969, pp. 72-93, ills. H. W. Krieger, The Colleclion of Primitive Weapons and Armor of the Philippine Islands in the United States National Museum (Smilhsonian Institution, Bulletin 137); Washington, 1926, pp. 27-28.

(2) Shariffuddin et Harrisson ont relevé quelques témoignages concernant Bornéo : T. Harrisson, "Brunci Cannon : their role in Southeast Asia (1400-1900 AD) ", Brunei Museum .Jl., I/1, 1969, pp. 94-118, ills. En ce qui concerne les Philippines, outre les quelques documents cilés ici d'après les textes espagnols, on pourra se reporter à l'abondante documentation sur les $\mathrm{xvI}^{\mathrm{e}}$ el $\mathrm{XvI}^{\mathrm{e}}$ siècles traduite par Blair et Rohertson dans leurs volumes II à V (Index, vol. LV, s.v. Moros: weapons and warfare el s.v. Military affairs: artillery) (H. Blair et J. A. Robertson, The Philippine Islands, 1493-1898; Gleveland, 1903-1909, 55 vols). Gibson-Hill donne aussi quelques témoignages tirés surtout de Crawfurd "Notes on the Old Cannon found in Malaya ", Jl. Malayan Br., Royal Asialic Soc., XXVI/1, 1953, pp. 145-174).

(3) Commenlarios do Grande Afonso Dalboquerque, $3^{\mathrm{e}}$ partie, chap. 28 (p. 145 (le l'éd. de 1774).

(4) João de Barros, Da Asia, Déc. II, livre 9, chap. 4 (fol. 354 de l'éd. de 1777).

(5) Lettre de 1537 à Charles Quint publiée par Navarrete in Collection de los Viajes ..., vol. V, p. 431 (Madrid, 1837).

(6) História das ilhas de Maluco, in A. B. de Sá, Documentacão para a história das missões do Padroado porlugues do Orienle - Insulindia, Lisboa, 1954-58, vol. III, p. 322. 
jusqu'à cent "berços », terme ancien portugais désignant de petites pièces d'artillerie à culasse ouverte (1). Une gravure hollandaise de 1601 montre bien ces pièces sur la plate-forme d'un kora-kora de Ternate (2). Sur cette même gravure, un navire do guerre de Madura est armé, aux pieds des châteaux avant et arrière, de pièces dont on distingue bien les culasses ouvertes avec leurs boîtes. Celles montées à l'avant semblent être à canons multiples, comme on en connaît encore des exemplaires à Brunei ou en Malaysia (3). Les "fustes ou galéotes" de Banten apparaissent sur unc autre gravure hollandaise armées de trois pièces à boîtes de chaque bord (Pl. XIV $n^{0}$ 1) (4). Tom Harrisson a publié un dessin tiré de Marryat (1848) qui représente

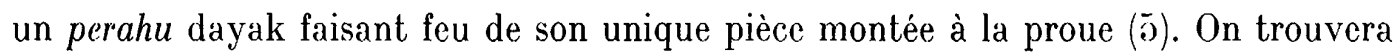
dans le récit du voyage de Van Noort en 1600 une gravure de "La nef ou prau royale de Borneo " portant deux canons à sa proue (Pl. XIV no 2) (6).

La relative légèreté de l'ensemble de ces pièces en faisait donc l'armement idéal pour le combat naval à bord de petites unités rapides à voile et à rames qui, à en juger par les récits des batailles avec les Portugais, semblent avoir constitué l'essentiel des flottes de guerre nousantariennes. Flles ont dû composer (et c'est peut-être encore le cas de nos jours) l'armement de choix des pirates nombreux en ces caux et des navires marchands soucieux de s'en protéger (7). A l'exception de celles des korakora de Ternate, posées sur des affûts, ces pièces sont toutes montées sur des fourches dont le pivot est enfoncé dans les lisses des navires (seules les pièces $\mathrm{C}$ et $\mathrm{D}$, parmi celles présentées ici, ont conservé cette fourche).

Mais ces canons étaient aussi utilisés pour défendre les palissades et estacades fortifiées, usage qui est, lui aussi, largement attesté dans les sources européennes dès le $\mathrm{XvI}^{\mathrm{e}}$ siècle (8). Les Espagnols, à leur arrivée dans la baie de Manille en 1564, la trouvent fortifiće et armée d'une abondante artillerie. Et lorsqu'cux-mêmes construiront dans cette ville la forteresse de Nuestra Señora de Guia, dans les années 1585,

(1) Les pièces d'artillerie les plus anciennes pouvaient être chargées par la culasse, où venait s'encastrẹ une boîte qui recevail la charge (d'où l'expression "canon à boîte "). Le tcrme bergo (barce ou berce dans le français du xvre siècle) a l'avanlage de préciser qu'il s'agit d'une pièce à boîte. Les autres termes utilisés dans les sources portugaises sont falconele ou espingardão. Le premier, qui correspond au français fauconneau, ne permet pas de préciser si le canon était ou n'était pas à boîte. Le deuxième, plus vague, puisqu'il ne s'agit que de l'augrmentatif de espingarda (fusil), caractérise bierı cette artilleric très lègère et de faible calibre, désignée dans l'ancienne marine française par le terme de pierriers. L'anglais, toujours pratique, comprend toutes ces bouches à feu légères, monlées sur des fourches pivotantes, sous l'expression swivel-guns (canons à pivol).

(2) Het tweede hoeck. Journael oft Dagh-Register ..., Middelburgh, 1601, pl. 17.

(3) Shariffuddin, op. cit., p. 85. Gardner, Keris and other Malay Weapons, Singapore, 1936, p. 93.

(4) D'eersle Boeck (...) door G.M.A.W.L. [Lodewijcksz], 1598, fol. $35 \mathrm{r}^{\mathrm{o}}$.

(5) Harrisson, op. cil., p. 96.

(6) Beschryvinghe van de voyagie ..., Amsterdam, 1602, fol. $71 \mathrm{r}^{\circ}$.

(7) C'est par l'intermédiaire de marchands chinois ou portugais de Macao que ces canons sont vraisemblablement parvenus dans les colleclions portugaises.

(8) Cf. les divers chroniqueurs portugais de l'époque, Barros, Couto, Correa, etc. Voir aussi : Jorge de Lcmos, IIisloria dos Cercos que (...) os Achens e Jaos puserão a forlaleza de Malaca, Lisboa, 1585. 
ils feront appel à un "indio » de la province de Papanga, nommé "Pandapira " et à ses enfants (1). Linschoten, à la suite de la prise de Johor Lama par les Portugais en 1587, décrit en ces termes les pièces ramenées à Malaka, puis en Inde : « (...) certaines d'entre elles ont la taille d'un mousquet, et d'autres sont plus grandes, et il y en a aussi de toutes sortes, très adroitement fondues et ornées de fleurs et de personnages (...)» (2). Le nombre des canons pris à Johor varie largement suivant les sources, mais il semble qu'il faille retenir un chiffre approchant du millier, dont moins d'une dizaine de grosses pièces. Diogo do Couto décrit bien leur disposition sur les estacades malaises (3).

Quant aux deux pièces les plus petites (C et D), qui sont en même temps les plus décorées et constituent de véritables chefs-d'œuvre, on peut penser qu'elles ont pu avoir aussi un usage cérémoniel, usage attesté pour des pièces comparables à Brunei (4).

$$
\text { ** }
$$

Aucun des canons légers de ce type inventoriés jusqu'ici dans l'Archipel n'est daté. L'inventaire lui-même est loin d'être encore exhaustif. Si l'on excepte les travaux de Gardner, très superficiels, et de Shariffuddin, qui concernent exclusivement Brunci, rien, à ma connaissance, n'a été fait pour les pièces qui peuvent encore exister dans le monde nousantarien (5). Le Field Museum of Natural History de Chicago possède à lui seul une collection qui semble importante (6). Il est donc exclu de pouvoir procéder encore à des datations, même approximatives, des pièces présen-

(1) Antonio de Morga, Sucesos de las Islas Filipinas (éd. Retana), Madrid, 1910, pp. 19, 26.

(2) The volyage of J.H. van Linschoten to the East Indies (Burnell \& Tiele, eds.), IIalkluyt Society, I.ondon 1884, vol. 1, p. 110.

(3) Mac Gregor, "Johore Lama in the 16th century", Jl. Malayan Br., Royja! Asialic Soc., XXVII/2, $1955, \mathrm{pp}$. 111-112, auquel on pourra se reporter pour les citations et la discussion de ce probleme.

(4) Cf. Shariffuddin, op. cit., et IIarrisson, op. cit.

(5) Krieger op. cit., pp. 26-30), en décrivant sommairement l'usage de l'artilleric aux Philippines, ne fait que citer, sans en donner d'illustration, quelques canons conservés dans les colleclions du National Museum, dont un seul lantaka ramené de Jolo, de 106,6 cm de long et de $3,5 \mathrm{~cm}$ de calibre, montí sur pivol; une sorte de crosse semble y être attachée : "a palm wood strip is lashed to the underside of the gun barrel by means of rattan splints."

(6) Collection mentionnée par Harrisson, op. cil., n. 10, p. 113. Par ailleur's, j'ui p'levé dans l'ouvrage de Egerlon of Taton (A description of Indian and Orienlal Armour, London 1896, pp. 153-154) la description d'un canon pris à des pirates de Bornéo par Rajah Brook et offert au souverain britannique. Il se trouvait à l'époque au chateau de Windsor : "a gun of pale bronze (...) the barrel is 6ft. 9in. long, of which the half (3ft. lin.) nearest the breach is octogonal, and the remainder circular. The diameter at muzzle as far as the trunnions is $5 \mathrm{in}$., at breach $9 \mathrm{in}$. There is on the barrel a raised floral ornament $1 / 4$ of an inch in relief in triangular panels of a South-indian character. The touch hole is heart shaped. "Cette description correspond à une pièce plus importante, mais de facture identique à celle de nos pièces A et B. Mudie signale de nombreux "swigel-guns " malais à Singapour, dans des collections privées (Mariner's Mirror, XXXII, 1946, p. 185) et G. G Wooley semble avoir rédigé une note sommaire après en avoir examiné un certain nombre en Malaysia ("Malay Cannon", Jl. Malayan Br., Royal Asiatic Soc., XX/2, 1947, pp. 35-38). 
tées ici ; à l'exception, toutcfois, de la pièce $\mathrm{F}$, qui porte deux inscriptions javanaises dont l'étude paléographique permet de proposer le XvII e siècle (infra, Appendice I).

Les nombreuses études de K. G. Crucq, publiées entre 1930 et 1941 dans le Tijdschrift de la Bataviaasch Genootschap, concernent entre autres quclques pièces célèbres dont l'origine est nousantarienne. Mais ce sont toutes des pièces d'importance beaucoup plus considérable que celles dont traitc cet article. Atteignant jusqu'à 3,45 mètres de long, avec un poids d'environ 6 tonnes (Ki Amuk à Banten), elles ne pouvaient être utilisées que sur des affûts fixes, pour la défense de forteresses en dur. Un petit nombre d'entre elles sont datées avec précision par Crucq. On notera seulement que ccrtains motifs décoratifs, plus rares sur ces gros canons, sont comparables à ccux qui ornent certaines des pièces présentées ici. C'est le cas, par exemple, des motifs en forme de losange dont est décoré le $K i$ Amuk, autour de son canal de lumière (1).

Les canons présentés ici sont faits d'un alliage à base de cuivre, du bronze vraisemblablement (2). Les fortes cargaisons de cash chinois importées dans tout le monde nousantarien pour y servir de numéraire dès au moins les Tang ont vraisemblablement constitué aussi un apport de cuivre pour la fonte de canons (3). L'étain, deuxième élément constitutif du bronze, est la production par excellence du monde malais. I.es techniques de la fonte n'ont pas à ma connaissance été décrites. Linehan a recueilli, dans l'état de Pahang, des fragments de moules en terre cuite ayant vraisemblablement servi à fondre, à la cire perdue, de petits canons. Il date le site, qui aurait ćté "siamois ", des $\mathrm{xIV}^{\mathrm{e}}$ et $\mathrm{Xv}^{\mathrm{e}}$ siècles, sur des donnćes tout à fait insuffisantes (4). En 1570, à Luson, les Espagnols ont pris une fonderie où ils ont trouvé des moules en terre cuite et en cire (5).

En ce qui concerne la provenance exacte des pièces dont il est question ici, à l'exception de celle, javanaise à n'en pas douter, exposéc à Macao, il n'est pas possible de se prononcer. On a vu qu'on ne pouvait se fier aux indications d'origine proposées par le Musée Militaire de Lisbonne, bien qu'une origine philippine ne puisse être à priori exclue. Quatre d'entre elles sont ornées de motifs communs à l'ensemble des cultures nousantariennes, que ce soit les motifs triangulaires, dits lumpal en javanais, ou le crocodile qui orne la seule pièce C. Les anses en forme de

(1) J'ai pu examiner des photos de ce canon communiquées par Denys Lombard. Cf. aussi Crucq, Tijd. Bataviaasch Gen., LXXVIII/3, 1938, pp. 359-381, article non illustré.

(2) Ce matériau était déjà largement utilisé au xvie siècle, comme l'attestent les diverses sources ibériques citées. On trouve cependant de rares mentions de l'usage du fer forgé (Morga, op. cit., p. 175 : "antes tenian versos de bronze y otras piezas de hierro colado "; Commentários ..., 1774, IIl, p. 144). On rappellera que cette dernière lechnique, inférieure en qualité à la fonte du bronze, a été utilisée en Europe jusqu'à la fin du Xvic sièclis (Cipolla, Guns and Sails in the Early phase of European Expansion, London, 1965, p. 24).

(3) Saint John affirme que le bronze des canons de Brunei était ainsi obtenu "from selected chinese brass cash " (Life in the Forests of the Far East, London, 1862, vol. 2, p. 298).

(4) "Some discoveries on the Tembeling", Jl. Malayan Br., Royal Asiatic Soc., VI/4, 1928, pp. 66-77, ills.

(5) Blair et Robertson, op. cil., vol. III, p. 103. 
dauphin de la pièce D, que l'on retrouve sur d'autres pièces de la région, sont vraisemblablement d'origine occidentale ; mais elles jouent ici un rôle purement décoratif, sur une très petite pièce qui peut fort bien être tenue à bout de bras et qui n'a pas besoin de ces accessoires pour être hissée à bord ou sur une palissade. Si les caractéristiques d'ensemble de nos pièces $\mathrm{A}$ et $\mathrm{E}$ sont tout à fait comparables à celles décrites tant par Gardner que par Shariffuddin, seule l'une de celles figurant sur une illustration de Gardner (fig. 70, no 3 ) semble être une réplique quasi exacte de la pièce D. En s'appuyant sur une remarque de Gardner (p. 93), qui affirme que les canons fondus à Brunei sont plus abondamment décorés que ceux de la péninsule malaise, et sur les thèses de Shariffuddin et de Harrisson, qui tendent à faire de Brunei un centre important de diffusion des techniques de fonderie en Asie du sud-est, tout au plus pourrait-on dire que les pièces les plus élaborées ( $G$ et $D$ ) ont de bonnes chances de provenir de ce sultanat. Mais n'est-ce pas là donner plus d'importance qu'elle n'en a à une région mieux connue, où l'on a effectué une collecte bien plus systématique des pièces existantes et, de plus, une région qui a mieux su préserver son patrimoine culturel ?

Par quels termes désignait-on ces canons dans le monde nousantarien ? Le "lantaca " des étiquettes du Musée Militaire, c'est le tagalog lantaka (1). C'est aussi le malais rentaka. Mais, selon la classification de Gardner pour la Malaysia continentale, ce terme aurait servi à désigner des canons plus importants et, du moins, très différents d'aspect. C'est à la catégoric des lela qu'ils appartiennent plutôt, toujours selon Gardner (2). Pour Brunei, selon Shariffuddin, ils doivent être rangés dans les catégories des bedil (3). A Java, en ce qui concerne du moins la pièce F, c'est aussi le terme bedil qui était utilisé, comme l'atteste l'inscription de ce canon (infra, Appendice I) (4).

Ces quelques remarques d'ensemble, avant de procéder à une description détaillée de chacun des six canons, gardent un caractère très général. L'absence totale d'indi-

(1) Maring \& Maring, Historical and Cultural Diclionary of the Philippines, Metuhen, 1973, s.v. (" bronze cannons used by pre-spanish Filipinos and present day Moros").

(2) En ce qui concerne le terme lela et sa possible étymologic, on notera que, parmi les canons utilisés au Gujräl au Xvre siècle, il y avait une très grosse pièce d'origine égyptienne portant le nom de Laylah. La démarche pourrait donc en ce cas être parallèle à celle qui, pour des canons plus importants, a généralisé en Malaysia le terme meriam, dont l'origine est le nom propre arabe Miriam. Ce dernier désignait d'ailleurs aussi des canons dans l'Inde musulmane (sur ces canons utilisés en Inde, cf. S. A. Z. Nadvi, "The use of Cannon in Muslim India ", Islamic Culture (Hyderabad), XII, 1938, pp. 405-418). Ces remarques vont dans le sens d'une introduction par l'ouest de ces techniques. Mais on ne doit pas négliger non plus les apports chinois fvoir à ce propos, infra, p. 244).

(3) Sur l'étymologie de ce mot d'origine tamil (<wěllil) el son passage, par l'intermédairc du malais, dans les diverses langues nousantariennes, cf. H. Kern, "Oorsprong van het maleische woord bedil ", Bijdragen tot de taal-, land-en volkenkunde van Netlerlandsch Indie, I.IV, 1902, pp. 311-312. C'est donc encorc un mot venu de l'ouest qui sert à désigner une arme à feu.

(4) L'usage fréquent, dans la toponymie de la Malaysia, tant continentale qu'insulaire, des lermes bedil, meriam, lela et, plus rarement, rentaka, confirme le ròle important joué par ces armes dans la région (Cf. : Malaysia, Singapore and Brunei. Official standard names gazeleer. US Army Topographic Command, Washington, 1970, s.v.). 
cations d'origine pour cinq d'entre ces pièces en est partiellement la cause ; mais c'est surtout l'état rudimentaire des connaissances en la matière qui est ici en question. Il s'agit, dans l'immédiat, de procéder à l'inventaire et à la description des pièces existantes. C'est la principale ambition de cet article.

PIÈce A (Pl. I ; Pl. VI, no 1).

Longueur hors-tout : $1310 \mathrm{~mm}$.

Calibre: $35 \mathrm{~mm}$.

Canon de section circulaire dans sa partie antérieure, orné, vers la gueule, de six moulures triangulaires (motif dit tumpal) portant des dessins floraux. De section octogonale dans sa partie postéricure, il est orné, côté culasse, de huit moulures triangulaires identiques aux précédentes; à la hauteur des tourillons, les huit faces de l'octogone s'achèvent sur un motif en creux, en forme d'accolade.

Côté gueule, le canon est entouré de trois anneaux circulaires. La gueule reprend, cn un motif crénelé à huit éléments, les huit côtés de la section octogonale. Avec son bourrelet très accentuć, qui lui donne un aspect évasé, elle a un diamètre très supérieur à celui de l'âme (135 mm contre $35 \mathrm{~mm}$ seulement de calibre); cette caractéristique semble bien être commune à la plupart des pièces fondues dans le monde insulindien.

Le canal de lumière est au centre d'une platine carréc en relief. Doc part ct d'autre de cette platine, il y a deux saillies de section rectangulaire. Sur certaines bouches à feu européennes, elles servent à fixer une sorte de petit couvercle destiné à protéger des intempéries la poudre du canal de lumière. Mais elles sont alors percées ; ce n'est pas le cas des pièces $\mathrm{A}$ à $\mathrm{D}$, la pièce $\mathrm{E}$ étant la seule à les avoir percées. Il semble donc que leur rôle d'originc ait été oublié et qu'clles n'aient été préservées sur ces canons qu'à des fins décoratives.

La pièce est munie de deux tourillons, mais la fourche n'a pas été conscrvée.

Le guidon de mire, cassé sur cette pièce, semble avoir eu la même forme lovée que celui de la pièce $\mathbf{B}$.

La culasse est ornée d'anneaux circulaires. Le bouton de culasse, cylindrique, est creux et on pouvait vraisemblablement y emmancher une crosse en bois, pour plus de maniabilité.

PiÈce B (Pl. I ; Pl. VI, no 2 et no 3 ).

Longueur hors-tout : $1350 \mathrm{~mm}$.

Calibre : $35 \mathrm{~mm}$.

Ses caractéristiques d'ensemble sont quasiment identiques à celles de la pièce A, à ceci près que la section ronde du canon est ornée, à hauteur des tourillons, de huit 
motifs triangulaires. La face supérieure de la section octogonale est ornée d'un losange allongé portant, comme tous les motifs triangulaires de cette pièce, des dessins foliés. Son guidon de mire, quasiment intact, est de forme lovée.

PIÈce G (Pl. II ; PI. VII, no 1 et no 2$)$.

Longueur hors-tout : $690 \mathrm{~mm}$.

Calibre : $20 \mathrm{~mm}$.

Canon de section circulaire dans sa partie antérieure, orné, côté gueule, de six motifs triangulaires en relief portant des dessins foliés et des triangles. Dans sa partie postérieure, de section octogonale, il est orné, côté culasse, de sept triangles identiques aux précédents. La face supérieure de la section octogonale porte, au lieu du huitième motif triangulaire, un crocodile en fort relief, dans la ligne de mire.

Côté gueule, le canon est entouré de deux anneaux. La gueule, crénelée en huit éléments, est identique à celle des pièces $\mathrm{A}, \mathrm{B}$ et $\mathrm{D}$. Sur la culasse, à son diamètre maximum, la section est identique à celle de la gueule, avec huit créneaux reprenant les huit faces de la section octogonale du canon.

Le canal de lumière est à la base d'une platine en relief en forme de trapèze. De chaque côté de la platine, on retrouve, comme sur les pièces A, B et D les saillies dont l'usage semble être perdu.

Le guidon, très protubérant sur cette pièce, est un motif bifolié.

Le bouton de culasse, comme sur les cinq autres pièces est cylindrique et creux.

Une fourche est encore montée sur les deux tourillons.

PIÉCE D (Pl. II ; Pl. VII, no 3 ).

Longueur hors-tout : $870 \mathrm{~mm}$.

Calibre : $20 \mathrm{~mm}$.

Légèrement plus gros que le précédent, ce canon est de facture très proche. Seul le décor en diffère.

Au-dessus des tourillons, il porte deux anses en forme de dauphins, motifs très fréquents sur les pièces européennes. Ces anses, qui servent normalement à lever des pièces lourdes, n'ont ici qu'un usage décoratif.

Sur la face supérieure de la section octogonale du canon, on trouve, outre le huitième triangle, un motif en relief formé de deux losanges superposés, surmontés d'une boule (dans la lignc de mire). Dans le huitième triangle, sur la face supérieure, plus petit que les sept autres, s'inscrit en relief une platine carrée entourant le canal de lumière.

Les dessins ornant les triangles tumpal et les losanges diffèrent légèrement de ceux de la pièce $\mathrm{C}$.

Le guidon, enfin, diffère dans sa forme de celui de la pièce $\mathrm{C}$.

Ce canon a, lui aussi, conservé sa fourche. 
Pièce E (Pl. III ; Pl. VIII, no 1).

Longueur hors-tout : $1680 \mathrm{~mm}$.

Calibre : $40 \mathrm{~mm}$.

De facture nettement différente des quatre précédents, ce canon est aussi le plus gros. Sa section est entièrement circulaire. A l'exception des anneaux qui l'entourent côté gueule et de ceux qui marquent sa culasse ct son bouton, il ne porte aucun ornement.

Le canal de lumière est au centre d'une moulure à quatre pétales. Les deux saillies de part ct d'autre de cette platine sont percées (ce qui n'est pas le cas, on l'a vu, des quatre pièces précédentes): on peut donc penser qu'elles ont pu servir ici à fixer la pièce destinée à protéger le canal de lumière. Le guidon de mire, de section simplement rectangulaire, porte un cran de visée. Le bouton de culasse, lisse, légèrement tronconique, est, lui aussi, évidé.

Cette bouche à feu, dont les divers organes ont gardé leur usage d'origine et qui est dépouilléc de tout décor inutile, semble nettement plus fonctionnelle que les précédentes. Il s'en dégage une impression d'ensemble assez différente. Cela tient-il à une date de fonte différente ? Ou bien, malgré des caractéristiques d'cnsemble qui en font certainement une pièce nousantarienne, provient-clle d'une région différente (peut-être les Philippines)?

PIÈce F (Pl. III ; Pl. VIII, no 2 et no 3 ; Pl. IX, nº 1).

Longueur hors-tout : $1630 \mathrm{~mm}$.

Bouche tromblonnée.

Les caractéristiques techniques, comme les motifs qui l'ornent, distinguenl complètement cettc bouche à feu des cinq précédentes.

Contrairement aux pièces $\mathrm{A}$ à $\mathrm{E}$, dont l'âme est cylindrique et d'un diamètre égal jusqu'à la bouche, cettc pièce a une bouche évasée en entonnoir, caractéristique dont le fondeur a profité pour la décorer d'une gueule de naga largement ouverte. A la façon de nos tromblons, mousquetons à trompette ou espingoles, elle devait donc tirer à mitraille, des chevrotines ou, à défaut, des clous ou des pierres. Le contenu de cette charge s'éparpillait donc sur une aire considérable et, si leur portée était faible, ces pièces n'en étaient pas moins redoutablement meurtrières, lors des abordages par exemple.

Shariffuddin en décrit plusieurs de la sorte, dont la bouche est nue (bedil gargabus) (1) ou décorée, à la façon de cette pièce mais dans un style très différent, d'une tête de crocodile à gueule ouverte (bedil naga). Wooley (op. cit.) publie la photo

(1) Shariffuddin compare ce gargabus à l'anglais blunderbuss qui désigne un canon à bouche tromblonée. Mais le terme offre une similarité bien plus frappante avec le portugais arcabuz (arquebuse). 
d'une pièce à gucule de naga qui se trouvait avant la guerre à Brunei ; elle porte un décor excessivement élaboré, qui paraît avoir subi l'influence des modèles chinois. Gardner en présente deux pour la péninsule malaise (lela rambang et lela mulul katak).

La deuxième caractéristique particulière de cette bouche à feu est d'être une pièce à boîte. Sa culasse est en effet ouverte et une boîte vient s'y encastrer. C'est celle-ci qui reçoit la charge. Elle est bloquée en place par un coin métallique, qui s'encastre verticalement dans l'espace restant à l'arrière de cette boîte, et/ou par une tige passant par les deux orifices ménagés sur les côtés de la culasse (ni le coin, ni la tige n'ont été conservés avec cette pièce).

La boite, cylindrique, est percée d'un canal de lumière, au centre d'une platine qui constitue la queue (?) du motif en forme de reptile (?) scrvant de poignée. Comme on le verra plus loin, il semble bien que cette boite n'ait pas appartenu d'origine à cette pièce.

Le canon est de section circulaire ; mais, sur sa partic supérieure, il est surmonté d'un méplat représentant les écailles du naga et d'une crête verticale irrégulièrement dentelée. Trois anneaux entourent ce canon, de part et d'autre des tourillons et à l'arrière de la bouche.

Cette bouche est constituée par une tête de naga couronnée, à la gueule largement ouverte, au décor très élaboré ; sa facture est typiquement javanaise.

L'arrière du canon, avec sa culasse ouverte, est en forme de nacelle ailée. Ses deux méplats latéraux sont finement décorés de motifs floraux, comme l'est en partic sa face supéricure. Le fond en est arrondi (1). Les ouvertures pratiquées latéralement pour le passage de la tige servant à bloquer la boîte sont entourées d'une moulure à quatre pétales.

Ce canon porte un certain nombre d'inscriptions :

1 et $2(2)$ : Deux inscriptions javanaises sont finement gravées en creux sur le méplat supérieur gauche de la culasse ouverte et sur le dessus du bouton de culasse. On se reportera à l'appendice pour leur lecture (Pl. X, no 1 et no 2 et infra, Appendice I).

3 et 5 : Sur le méplat supérieur droit de la culasse ouverte, deux signes sont gravés en creux : une fleur à trois pétales et un signe pouvant ressembler à un visarga.

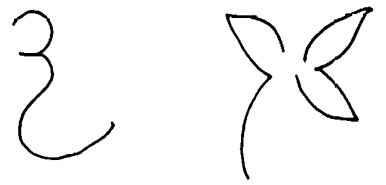

(1) La pièce F est maintenant inutilisable, car largement fendue sous sa culasse.

(2) Chacun des six numéros renvoie au numéro correspondant de la pl. III, où sont indiqués les empla. cements de ces inscriptions. 
4 : Sur la boîte, à droite de la poignée, il y a trois lettres : DAH. Elles sont en relicf et sont donc venues de coulée lors de la fonte de cette boîte, qui n'est par conséquent pas d'origine sur cette pièce javanaise. Flle a vraisemblablement remplacé, lors de son usage par les portugais, une première boîte défectucuse. Je ne suis pas en mesure d'interpréter ce sigle, mais je note tout de même qu'un faucon du Musée Militaire de Lisbonne, daté du Xvir e siècle, porte, avec des lettres de forme sensiblement identiques, le sigle AH.

6 : A droite du canon, légèrement en avant des tourillons, on trouve enfin, grossièrement gravées (donc postérieurement à la fonte du canon), le sigle suivant:

$$
10-t
$$

Shariffuddin décrit en ces termes la seule pièce à boîte qu'il ait inventoriéc à Brunei (contrairement à notre pièce $\mathrm{F}$, sa bouche n'est pas tromblonéc) : "Boal cannon. Last but not least of the "local " cannon is one with a long, smooth, octagonal barrel, $1230 \mathrm{~mm}$, the whole back end of which is shaped like an elaborate, square ended boat, perhaps a Javanese type or an ancient form in Brunei no longer known. This open breach in the boat-section is said to have been used for keeping smaller cannons, up to seven of them. I have been told by one senior Brunei nobleman that this bedil imitates a kind found in China. It is certainly unusual for Brunei, but not at all impossible. (...) an elaborate floral design, which also continues onto the front of the boat-section and along the sides. (...). This boat-cannon might be another example of individual variation (...) ; or otherwise of copying from China or Java locally, or just imported? The boat-cannon was purchased from Sipitang in the southern part of Sabah, outside Brunei. »(1).

Le fonctionnement de cette pièce semble bien avoir été oublié car la tradition localc, rapportéc par Shariffuddin, fournit une explication fantaisiste pour justifier de l'ouverture de la culasse. Il semble qu'il faille y retrouver le souvenir des boîtes multiples, que l'on utilisait à tour de rôlc avec ce type de canon, en les chargeant à l'avance, pour accélérer le rythme de tir (à en juger par l'illustration de Shariffuddin, il semble que la boîte de cette pièce n'ait pas été conservée; ce qui peut expliquer cette confusion).

Mais la partie la plus intéressante du commentaire de Shariffuddin tient à la présomption, fondée sur la tradition locale, d'une imitation de modèles chinois ou javanais. Sa comparaison avec notre pièce $F$, indiscutablement javanaise, semble bien confirmer qu'elle provient de cette île. 
En ce qui concerne l'imitation de bouches à feu chinoises, il semble bien aussi que la tradition locale soit fondée.

La seule bouche à feu à laquelle j'ai pu comparer la pièce $F$ n'est malheurement pas chinoise, mais viêlnamienne. Elle relève cependant, au moins partiellement, de la tradition chinoise. Le Musée de la Marine de Paris possède en effet une très belle pièce en bronze, prise en 1867 sur la citadelle de Châu-đốc, dont elle défendait l'entrée (1). Elle mesure environ $1,80 \mathrm{~m}$ de long et son calibre est de $32 \mathrm{~mm}$. Elle est montée sur un affût en bois sculpté et doré de facture viêtnamienne. C'est une pièce à boîte (trois d'entre ces boîtes ont été conservées). Elle représente un dragon à guculc ouverte (Pl. IX, no 2). Les caractéristiques techniques diffèrent par certains côtés de celles de la pièce $\mathrm{F}$ : boîte plus élaborée, venant parfaitement s'encastrer dans l'ouverture de la culasse, qu'elle obture complètement; sa bouche n'est pas tromblonée, malgré l'apparence qu'en donne la gueule ouverte du dragon. Stylistiquement, aussi, elle en diffère très nettement : la tête et la crête dorsale du dragon, à la chinoise, remplacent celles du naga, à la javanaise.

Mais l'impression d'ensemble qui s'en dégage, comme l'examen de certains détails, révèlent la conception tout à fait identique de ces deux pièces. La culasse ouverte dans laquelle vient s'insérer la boîte, en particulier, offre une ressemblance frappante avec celle de la pièce javanaise : même forme de nacelle ailée, aux méplats décorés, avec deux ouvertures pratiquées latéralement pour le passage de la tige servant à bloquer la boîte. Les motifs triangulaires cux-mêmes, qui entourent le canon côté culasse, ne sont pas sans laisser penser aux motifs lumpal des pièces nousantariennes (2).

Un type de canon comparable à celui de la pièce $\mathrm{F}$ a donc existé dans une région qui, si elle n'est pas la Chine même, n'en a pas moins subi, infiniment plus que Java, l'influence des techniques chinoises.

Les textes chinois du temps des Ming parlent assez abondamment des canons à boîte et de l'introduction, au début $d u x{ }^{e}{ }^{e}$ siècle, de cette technique qui semble avoir été étrangère à la Chine (3). Mayers (p. 96) (4) a traduit un passage du Wubei $z h i$ 武備志 (j. 122, 9a) : "[The guns] were perforated longitudinally, and five small

(1) Exposée, dans la galerie basse, sous le no 2104 trif. 41 AR 4 \% L'histoire de cette piece, el ses photos, ont éte aimallement fournies par le Service d'Éludes de ce Musée. La pièce avait élé offerte par l'Amiral de La Grandière au Prince Impérial. Le Ministère de la Marine en fit don au Musée en janvier 1868. C'est done lors de la prise de Chàu-đóc par l'Amiral-Gouverneur, en juin 1867, qu'elle fut enlevée, pour êl re aussilól c'xpédiće en France. Kie'n uc permet malheureusement de dater la fonte de la pièce.

(2) Pent-être faut-il voir là, sur une pièce vraisemblablement fondue dans la partie méridionale du Viêlnam, une influence stylistique d'origine cam. On sail par ailleurs combien la culture materielle cam a elé assimilée par I's Viêtnamiens du sud. Ceci rattacherail de fait cette pièce, par certains de ses aspecls, au monde nousantarien, en une démarche en quelque sorte inverse.

(3) Voir à ce propos : Pelliot, "Le Juōja et le Sayyid I!lusain de l'Histoire des Ming ", T"oung pao, XXXVIII, 1948, pp. 86, 199-207.

(4) Mayers, "On the introduction and use of gunpowder and firearms among the chinese ". Jl. Norih China Br., Royal Asiatic Soc., VI, 1871, pp. 73-104. 
barrels were used, which were loaded with powder in succession and placed inside the body of the piece, from which they were shot off. " Ce texte et l'illustration qui l'accompagne sont en fait extraits du Chouhai lubian 等海圆編 de 1562 (j. 13, 33a-35b). Ia planche, quoique fantaisiste, n'en est pas moins explicite en ce qui concerne les boîtes et la crosse qui vient s'insérer dans le bouton de culasse (Pl. XI, $n^{0}$ 1) (1).

Toujours en ce qui concerne les possibles apports chinois aux techniques javanaises, on sait par ailleurs que les Yuan avaient utilisé des bouches à feu lors de l'expédition de Kubilai Khan à Java, en 1293 (2). Et on a retrouvé dans cette même île une bombarde portant une inscription chinoise de 142l (3). Au début du xvire siècle, enfin, on sait que les Anglais se proposaient d'amener des canons à boîte d'origine chinoise aux Moluques, où ils ćtaient très demandés : "Brass pieces of ordnance with chambers in the breeches, which are to be had at Bantam, but brought from China as is thought" (4). Parallèlement à des apports venus de l'ouest, l'influence des techniques chinoises à Java paraît donc bien attestée.

On peut encore rappeler ici le premier témoignage, au $\mathrm{Xv}^{\mathrm{e}}$ siècle, de l'usage d'armes à feu par les Javanais : Ma IIuan, dans son Yingya shenglan, affirme à propos des cérémonies de mariage que le mari escortait sa nouvelle épouse au domicile conjugal au son des gongs, des tambours et des armes à feu (5).

(1) A ma connaissance, le débat reste encore ouvert, à savoir si ces canons, qui sont toujours qualifiés

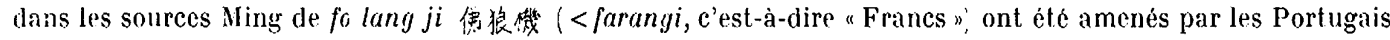
ou, comme le pense Pelliot (ibid.) étaient connus avant l'arrivée de ceux-ci (auquel cas les fo lang ji seraient les Tures byzantins j. Quelle que soil la solution de ce problème, si les pièces javanaises à boîte ont étć fondues sur des modèles chinois, c'est donc en dernier ressort d'une technique d'origine occidentale qu'elles relèvent.

(2) Schlegel, "On the invention and use of fire-arms and gunpowder in China ", T"oung pao, 111, 1902, p. I. Schlegel reprend aussi, dans cel article, à travers Raffles surloul, et d'une façon inadéquate, quelques temoignages tardifs de l'ulilisation d'artillerie dans les sources javanaises.

(3) Cette bouche à feu se trouve maintenant au Museum für Völkerkunde de Berlin (cf. Feldhaus, "Iïre chinesische stangenbuchse von 1421 ", Zeitschrifl für Historische Waffenkunde, IV, 1907, p. 256; Die Technik der Vorzeit..., Leipzig, 1914, col. 424).

(4) Lellers received by the East India Company from ils servants in the East, vol. I, p. 69, doc. 35, s. d. [1610-1611].

(5) L'expression fang huochong 方火銃 a été diversement traduite. On la retrouve lelle quelle dans le Yingya shenglan de Ma Huan (Feng Chengjun 溤承鈎, Yingya shenglan jiaozhu满涯滕筧校注, Shanghai,

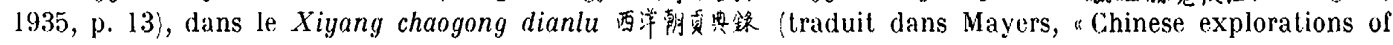
the Indian Ocean during the fifteenth century ", The China Review, IV, 1876, p. 178) ct dans le Xiyang fanguo $z h i$ 西洋番圈志 (éd. Xiang Dit, Pékin, 1961, p. 9) : ces deux derniers textes l'ayant vraisemblablemenl reprise à Ma Huan. Mayers a donné la traduction littérale de l'expression ("let off fire tubes") et Schlegel (op. cil., p. 6) a été plus catégorique encore ("fired guns"). Dans leurs traductions du Yingya shenglan, Groeneveldt ("Notes on the Malay Archipclago ...", Verhandelingen van het Bataviaasch Gen., XXXIX, 1880, p. 51) et, bcaucoup plus récemment, Mills (The Overall survey of the Ocean's shores, Hakluyt Soc., London, 1970, p. 95) n'ont pas admis un usage si ancien d'armes à feu à Java el, à l'encontre du sens-même de l'expression, l'ont traduite par "fire-works" ou "fire-crackers". L'existence d'armes à feu à Java à une date antérieure ou au moins contemporaine confirment les traductions de Schlegel et de Mayers (on sait aussi que huochong désignait. bien sous les Ming une arme à feu, utilisée dans les campagnes d'Annam ou contre les Mongols; cf. Pelliol, "Le Huồa ... ", p. 199, n. 232). On peut encore citer, en ce sens, le témoignage plus tardif de Raffles, selon qui les Javanais tiraient des coups de canons lors de leur cérémonies de mariage (Hislory of Java, II, p. 350) ou 
Tous ces éléments épars ne permettent malheureusement pas de préciser la datation de cette bouche à feu javanaise (pièce F) (1). C'est, en dernier ressort, l'étude paléographique des inscriptions qu'elle porte qui permet seule de proposer, sous certaines réserves, de dater ce canon du xvir ${ }^{\mathrm{e}}$ siècle.

Appendice I

\section{LES INSCRIPTIONS ET LA DATE DU CANON JAVANAIS (PIECE F)(2) par Riboet Darmosoetopo}

Dans les textes de wayang on connait un personnage en forme de serpent : c'est Nagaraja (roi des naga). La fille de Nagaraja, Nagagini, est épousée par Bima (Wrekudara) ; elle est la mère de Antarêja. La tête de serpent qui orne l'extrémité de ce canon porte une couronne (mahkota). Ce serpent est donc certainement considéré aussi comme le roi des naga.

Habituellement on reconnait bien la date d'un objet lorsqu'elle est inscrite soit en chiffres, soit avec un chronogramme (candra sengkala). Si ce naga contient un candra sengkala-mêmêt [c'est à dire sous forme symbolique], la date de ce canon pourrait être lue ainsi :

Naga raja warastra lunggal (3).

Naga a la valeur numérique 8 .

Raja a la valeur numérique 1 .

Warastra [c'est-à-dire bedil, le canon proprement dit] a la valeur numérique 5.

Tunggal [l'arme dans sa totalité] a la valeur numérique 1 .

On aurait donc : 1518 Saka $=1596$ EG (4).

celui de Shariffuddin (op. cit., pp. 90-91), qui atteste l'usage du canon lors des cérémonies de mariage de la maison royale de Brunei, et les dons de canons à la famille de la fiancée chez les Dusun.

(1) La technique, plus ancienne, du canon à boîte, n'en a pas moins été utilisée tardivement, jusqu'au Xvirl ${ }^{\text {e }}$ siècle en Europe, plus tardivement en Asie, à en juger par la pièce viêtnamienne prise à Ghâu-đốc en 1867. Aucune conclusion ne peut donc être tirée de l'utilisation de cette technique.

(2) [Monsieur Riboet Darmosoetopo (Fakultas Sastra dan Kebudayaan, Universitas Gadjahmada, Yogyakarta) a eu l'amabilité d'examiner sur photos la pièce javanaise et ses deux inscriptions. Qu'il soit ici remercié. On trouvera dans cet appendice la traduction française des informations qu'il m'a communiquées. Mes commentaires au texte de M. Riboet Darmosoetopo ont été rajoutés entre crochets.]

(3) Raden Bratakesawa, Kalerangan Candrasengkala, (Balai Pustaka) Jakarta, 1952.

(4) [Une première objection à cette interprétation est que tout bedil naga couronné porterait ainsi une date identique. Elle ne correspond en outre pas aux données fournies par l'étude paléographique.] 
Paléographie : Les inscriptions que porte ce canon sont en écriture javanaise. Mais il n'a malheureusement pas été possible de les lire en entier. Leur type d'écriture est identique à celui de l'inscription de la tombe de Bayat (Kabupaten Klaten, Surakarta), datée de 1555 Śaka = 1633 EC (c'est-à-dire sous Sultan Agung de Mataram).

Aksara qui ont déjà pu être déchiffrées :

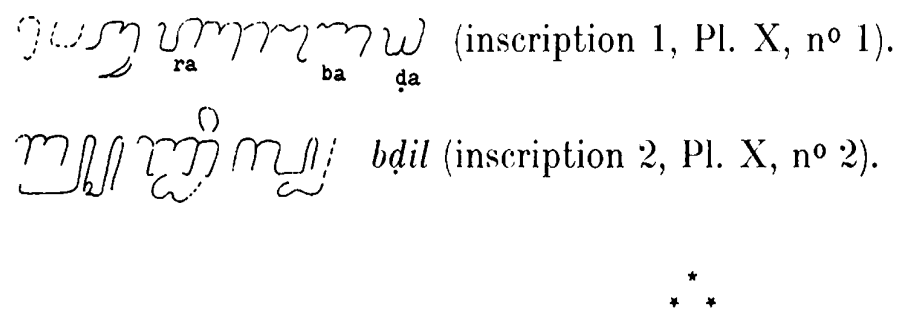

\section{AppendicE II}

TROIS CANONS CONSERVES AU MUSEE DE L'HOMME A PARIS (1)

Peu avant de mettre les pages qui précèdent sous presse, Christian Pelras m'a signalé l'existence, dans les collections du I)épartement d'Océanie du Musée de l'Ilomme, de trois petits canons dont la provenance était inconnue, mais qui, manifestement, étaient d'origine nousantarienne.

Il m'a scmblé nécessaire de joindre ici leur description, d'autant plus que j'ai pu les examiner bien plus à loisir que ceux conservés dans les collections portugaises et qu'une analyse de leurs alliages a pu être effectuéc (infra, appendice III).

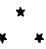

De l'examen conjoint de ces pièces, de celles de Lisbonne et de celles présentées par les articles cités précédemment, on peut dégager les quelques constantes qui suivent :

- fréquence de la division du canon en deux parties de sections respectivement, octogonales (côté culasse) et ronde (côté gueule). Dans les cas où les deux parties sont de section circulaire (pièce $\mathrm{E}$ et $\mathrm{I}$ ) une solution de continuité est néanmoins introduite en avant des tourillons, en donnant un diamètre supérieur à la partie postérieure du canon.

(1) Je dois remercier ici M"les Girard et Bataille, conservalrices au Département d'Océanie, qui m'ont permis d'examiner ces pièces et d'en obtenir des photographies. 
- Emploi général d'un bouton de culasse évidé dans lequel venait s'emmancher une crosse permettant de mieux pointer le canon pivotant sur sa fourche.

- Forte récurrence des motifs décoratifs triangulaires (lumpal) et du losange (dans la ligne de mire).

- Présence constante de deux saillies, de part et d'autre du canal de lumière.

- Présence presque constante d'anneaux autour de la section circulaire du canon.

- Fréquence du motif crénelé à huit éléments sur la gueule et la culasse.

- Rapport toujours identique entre un calibre faible et un grand diamètre de la bouche, largement évasée (ceci semble bien être une constante dans la fabrication des canons nousantariens, quelle que soit leur taillei.

PIÈce G (Pl. IV ; Pl. XII, nº $1 ;$ Pl. XIII, nº 1 et 2$)(\mathbf{1})$.

Longucur hors-tout : $940 \mathrm{~mm}$.

Calibre : $25 \mathrm{~mm}$.

Poids : $21 \mathrm{~kg}$.

Canon de section circulaire dans sa partie antérieure, orné, vers la bouche, de cinq moulures triangulaires (lumpal) ornées de dessins floraux. De section octogonale dans sa partie postéricure, il est orné, côté culasse de huit moulures triangulaires identiques aux prédédentes. Un motif folié en forme de losange, surmonté d'une boule, orne la face supéricure de la section octogonale.

Côté gueule, le canon est entouré de deux anneaux circulaires. La gueule reprend, en un motif crénelé à huit éléments, les huit côtés de la section octogonale; il en est de même pour la culasse.

Le canal de lumière est au centre d'une platine carrée en relief. On trouve de part et d'autre de cette platine deux saillies de section rectangulaire, non percées (cf. supra p. 239).

Le bouton de culasse, de section circulaire, est creux.

La fourche est encore montée sur ses deux tourillons.

Pièce H (PI. IV ; Pl. XI, nº 2 ; Pl. XII, no 2) (2).

Longueur hors-toul : $1060 \mathrm{~mm}$.

Calibre : $28 \mathrm{~mm}$.

Poids : $32 \mathrm{~kg}$.

Les caractéristiques d'ensemble de cette pièce, légèrement plus grosse, sont semblables à celles de la précédente.

Mais, à la hauteur des tourillons, elle porte deux anses en forme de dauphin. A la jonction des deux sections de son canon, octogonale et circulaire, elle est ornée d'anneaux en léger relief. De part et d'autre de ces anneaux, on trouve huit motifs triangulaires. Côté gueule, il y a aussi huit de ces motifs, portant les mêmes dessins.

(1) Cote X.44.166 du Département d'Ocćanie.

(2) Cote X.44.168 du Département d'Océanie. 
Les deux saillies, de part el d'autre du canal de lumière, sont percées (cf. supra, p. 239).

Le bouton de culasse porte encore des liens en rotin ayant servi à maintenir en place la crosse en bois qui y était enfoncée et dont un fragment brisé est encore conservé à l'intérieur du bouton.

PIÈce I (Pl. V; Pl. XII, no 3) (1).

Longueur hors-tout : $660 \mathrm{~mm}$.

Calibre : $25 \mathrm{~mm}$.

Poids : $7,5 \mathrm{~kg}$.

Des neuf canons présentés ici, c'est le plus petit. Il diffère assez nettement, dans le détail, des précédents, tout en conservant les caractéristiques communes à l'ensemble de ces canons.

De section entièrement circulaire, il est orné, côté culasse, de six motifs triangulaires aux dessins foliés. A hauteur des tourillons et côté gucule, il n'est entouré que de cinq motifs identiques.

Sur sa partic supérieure, il porte un motif floral en forme de losange, en léger relief.

Le canal de lumière est à la base d'une platine circulaire en léger relicf.

En arrière du canal de lumière, la culasse est ornéc de deux anneaux à six pétales.

Les motifs crénelés à huit éléments de la gueule et de la culasse diffèrent légèrement des précédents, mais le principe en est conservé.

La fourche, sur ses deux faces latérales, est ornée d'un motif folié.

Appendice III

\section{COMPOSITION DE L'ALLIAGE CONSTITUANT LES CANONS DU MUSEE DE L'HOMME (2)}

Des prélèvements de fragments de limaille ont été eflectués sur les trois canons. Lcur coulcur est jaune métallique, révélant ainsi un alliage de cuivre.

\section{Caraclérisalion des éléments}

L'analyse chimique qualitative indique la présence de cuivrc, de zinc, de fer el de traces de nickel. La réaction au manganèse est restée négative. La caractérisation

(1) Cote X.44.167 du Département d'Océanic.

(2) Résumé du Rapport sur l'analyse effectuée au Laboratoire de Minéralogie du Muséum d'Histoire Naturelle, par $M^{\text {me }}$ Pinet. Qu'clle en soit ici remerciée. 
par le procédé des attaques de Hiller révèle d'abord qu'il n'existe pas de différences fondamentales entre les trois prélèvements. Elle met en évidence la présence de cuivre, de zinc et de fer.

On est donc en présence d'un lailon.

\section{Dosage des éléments}

Effectué par absorbtion atomique, puis à la microsonde de Castaings, le dosage révèle que les trois canons sont constitués d'un laiton dont la composition moyenne est de l'ordre de $60 \%$ de cuivre, $30 \%$ de zinc, les $10 \%$ restants étant constitués par le plomb $(4 \%)$, le fer $(1,5 \%)$ et des traces de nickel.

\section{NOTE ADDITIONNELLE SUR LE LAITON EN ASIE DU SUI)-EST ET SON USAGE POUR LA FONTE DE CANONS (1)}

L'existence de canons en laiton, et non en bronze comme toutes les sources et études citées nous l'avaient fait attendre, pose bien évidemment un certain nombre de problèmes (2). Du fait que ces trois canons nousantariens sont, à ma connaissance, les seuls exemplaires dont l'alliage ait été analysé, il n'est pas possible ici de les résoudre tous $(3)$.

La confusion constante des lermes désignant le cuivre et ses alliages, jusqu'à une période récente et dans les langues les plus diverses, n'est pas pour faciliter les recherches en ce sens (4). Seules les sources ibériques, dont on a cité dans le corps de l'article quelques exemples, utilisent dès le xvi ${ }^{\mathrm{e}}$ siècle le terme "bronze " (5); mais c'est encore souvent le mot "métal " qui est donné, par opposition à "fer "

(1) Les résultals inattendus de cette analyse, qui me sont parvenus apres la mise sous presse de cet article, m'ont incité à aborder ici succintement le probleme posé par l'usage du laiton en $\Lambda$ sie du sud-est.

(2) On rappelera la différence entre ces deux alliages : le bronze est essentiellement constilué de cuivre et d'élain, le laiton de cuivre et de zinc. Dans les deux cas le cuivre reste l'élément prépondérant. D'autres mélaux interviennent généralement en quantités plus faibles dans ces alliages et modifient lẹırs propriétés (résislance, couleur, elc. .

(3) Il serait souhaitable que de telles analyses soienl effectuées sur des séries importantes de canons. Dans un premier stade, une simple analyse qualitative, aisément conduite sur des prélèvements qui ne détériorent pas des pieces de cette taille, peut permettre de distinguer rapidement les bronzes des laitons.

(4) C'est ainsi qu'il faut attendre la huitième édition du Dictionnaire de l'Académie (en 1932 !) pour y trouver une définition correcte du bronze.

(5) Mais on peut douter du témoignage de ces auteurs : habitués qu'ils étaient à ne concevoir leurs canons qu'en bronze ou en fer forgé, ils pouvaient pêcher par ethnocentrisme et ne voir que du bronze lorsqu'ils étaient en présence de laiton. Seule une analyse chimique permet de distinguer à coup sùr les deux alliages lorsque les objets sont patinés et oxydés. 
(forgé) (1). Le hollandais prête aussi à confusion avec "metaal», que l'on retrouve dès le $\mathrm{XVII}^{\mathrm{e}}$ siècle pour désigner les pièces d'artillerie nousantariennes. Il en est de même pour l'anglais "brass" qui, à cettc époque et jusqu'au moins la fin du $\mathrm{xvin}^{\mathrm{e}}$ siècle, peut désigner tant le bronze que le laiton.

En ce qui concerne ces trois pièces en laiton, la première question à se poser est de savoir si elles pouvaient fonctionner et si l'on connait d'autres exemples de canons fondus avec un tel alliage dans des aires culturelles différentes. On doit d'abord constater que le laiton est un alliage tout à fait propre aux fontes moulées. Les laitons les moins malléables, les plus résistants, sont ceux dont le pourcentage de zinc avoisine les $30 \%$; c'est précisément le cas de l'alliage de nos trois canons (2). Vu la forte épaisseur des parois des canons nousantariens par rapport à leur faible calibre, ces pièces avaient donc toutes les chances de pouvoir supporter les contraintes provoquées par le tir. L'un d'entre eux au moins a certainement d'ailleurs fonctionné puisqu'il porte encore les restes d'une crosse en bois (pièce $\mathrm{H}$ ). On sait par ailleurs que des canons en laiton ont été fondus vers 1535 en Angleterre (3).

En ce qui concerne l'Asie, je n'ai pu retrouver qu'une seule mention d'un canon fondu en un alliage qui semble bien être un laiton. En 1629, la galère amirale de la flotte d'Atjéh venuc assiéger Malaka, prise par les Portugais et envoyéc à Goa avec à son bord le laksamana prisonnier, était armée d'une centaine de pièces d'artillerie ; l'une d'entre elles seulement était faite de "tambaca " et avait une grande valeur marchande (4). Le problème est donc de savoir ce que désigne ce terme. C'est le malais-indonésien lembaga (5), qui désigne à l'heure actuelle exclusivement le cuivre, lorsqu'il est utilisé sans qualificatif. Mais bien des éléments laissent penser qu'il a eu auparavant une acception plus large, regroupant en un seul terme générique le cuivre et ses alliages, dont en particulier le laiton.

Le Malay-English Dictionary de Wilkinson, construit en bonne partie sur la

(1) L'acception du mot "métal " esl alors plus vaste qu'aujourd'hui el englobe les alliages, dont le bronze et le laiton. On le trouve souvent opposé au fer forgé : voir par exemple cettc phrase des Commentários do Grande Afonso Dalboquerque (1557), à propos des canons trouvés en 1511 à Malaka : "Tomáran-sc tres mil tiros de artilheria, e destes seriam dous mil de metal... os outros eram de ferro da feição dos nossos berços. " ("On prit trois mille pièces d'artillerie, dont deux mille en métal... les autres étaient en fer, à la manière de nos barces ", IlI Ie partie, chap. 28 ; p. 144 de l'éd. de 1774).

(2) Kirk-Othmer, Encyclopedia of Chemical Technology, New York, 1967, vol. VI, p. 217. Mais la présence de plomb et de fer dans cet alliage tendrait au contraire à diminuer sa résistance aux chocs.

(3) M. Daurnas (éd.), Histoire générale des techniques, Paris, 1965, vol. II, p. 91.

(4) La description de ces événements el de cette galère, nommée "Espanto do mundo " (Épouvante du monde), est donnée dans : Manoel Xavier SJ, Vilórias do Governador da India Nuno Alvares Botelho, Lisboa, 1633, fol. 20 ro. Elle est reprise par l'historien Faria e Sousa, Asia Porluguesa, Lisboa, 1675, vol. III, pp. 443-444, qui ajoute, à propos du "tambaca ", qu'il s'agil d'un métal "vertueux et estimable". Cf. aussi, sur le récit de ces événements, les documents publiés par G. R. Boxer, "The Achinese Attack on Malacca in 1629, as described in Contemporary Portuguese Sources ", in : J. Bastin et R. Roolvink (éd.), Malayan and Indonesian Studies, Oxford, 1964, pp. 105-121.

(5) A l'origine de tembaga, on trouve le prākril tamba- (skr. tāmra-; coulcur de cuivre) et sa formc dérivée tambaga (cuivre; skr. tāmraka). J. Gonda, Sanskiti in Indonesia, New Delhi, 1973, p. 91 ; H. Kern, Verspreide Geschriflen, 's-Gravenhage, 1922, vol. X, pp. 151, 277. 
littérature malaise classique, est le seul à gloser le mot par "copper " et «brass" (1). D'autres langues de l'Archipel ont par ailleurs conservé pour les termes apparentés à tembaga le sens de laiton (2). On trouve aussi dans les divers dictionnaires malais et indonésiens une liste des qualificatifs qui sont nécessaires pour préciser la nalure exacte de l'alliage, mais aussi du métal pur (3). Le terme est par ailleurs attesté en vieux javanais et en vieux balinais dès au moins le Ixe siècle (tãmra/tāmbra; tambaga/tamwaga) et il y apparaît souvent accolé ou opposé à un terme désignant un autre alliage, qui servait à la fabrication des cloches, c'est-à-dire le bronze (gangsa/kangsa <skr. et pkr. kamsa-; malais moderne gangsa/kangsa, synonyme de tembaga perunggu). Il y désigne aussi très précisément l'alliage à base de cuivre dans lequel sont gravées les chartes et qui est vraisemblablement un laiton (4). L'actuel terme chinois servant à désigner le laiton (鍮 tou) aurait pour sa part le même étymon (skr. lāmra-) que le malais tembaga et il aurait été introduit en Chine depuis l' Inde avec le bouddhisme (5) (et on sait le rôle joué par les centres bouddhiques sud-est asiatiques dans la propagation vers l'est de cette religion). Le terme malais (ou des termes indiens apparentés) est passé dans les créoles luso-asiatiques et anglo-indiens et de là dans les diverses langues européennes où il désigne le plus souvent le laiton, mais parfois aussi un alliage comprenant de l'or (tembaga suasa) (6).

(1) Cet auteur cite deux expressions dans lesquelles l'idée d'alliage est bien mise en évidence : jangan lietembagaan uji (littéralement: que la pierre de touche ne révèle pas sa nature d'alliage de cuivre ; Wilkinson traduit par "let not the touchstone show them up as brass ») ; il donne aussi le dicton tuan mas, sahaya tembaga, élégamment traduit par "golden is my lady, common brass am 1 ".

(2) Gonda, op. cil., pp. 93. 119.

(3) Tembaga merah : cuivre rouge (cuivre métallique pur); l. kuning : cuivre jaune (laiton); $l$. perunggu: bronze; $t$. putih : cuivre blanc (cupro-nickel, le paktong chinois); l. suasa : alliage de cuivre ou de laiton el d'or.

(4) Gonda, op. cil., pp. 93, 381-382 ; L.-C. Damais, Réperloire onomastique de l'épigraphie javanaise, Paris, 1970, pp. 446, 449, 748; F. Goris, Prasasti Bali, Bandung, 1954, pp. 53, 120, 257, 283, 317 ; cf. aussi la charte de 1405 traduile par Brandes in : Nolulen Bataviaasch Gen., XXXVII, 1899, pp. 64-69.

(5) Chang IJung-chao, "Now Researches on the Beginning of the Use of Zinc in China ", Bul. Chinese Geological Soc., IV/1, 1925, pp. 125 sq., cité par Needham, Science and Civilisation in China, Cambridge, 1974, vol. V/2, p. 203.

(6) S. R. Dalgado, Glossirio luso-asiático, Coimbra, 1921, vol. II, p. 346, s. v. lambaca el H. Yule et A. C. Burnell, Hobson-Jobson, L.ondon, 1903, p. 929, s. v. Lombacti. Ci. aussi $\Lambda$. Marre, "Index des mots malais francisés", Mém. Soc. Acad. Indochinoise, I, 1877-78, pp. 143-144 (s. v. Lombac et souassa); M. Devic, Diclionnaire étymologique des mols d'origine orientale, dans le supplément au Littré (s. v. tombac); l'Oxford Diclionary (s. v. lombac); le diclionnaire portugais de Moraes (éd. 1844, s. v. lambaga); etc. Le mot fait encore partie aujourd'hui du vocabulaire de la langue portugaise parlée à Timor, où il désigne le laiton, mais parfois aussi le cuivre et même le bronze (L. F. Reis Thomaz, "Timor, notas histórico-linguisticas ", Porlugaliae Historica, II, 1974, p. 266). Tanl le Gilossário de Dalgado que le IIobson-Jobson relèvent un certain nombre de cilations d'auteurs européens, dont la confusion ne permet pas de mieax préciser la signification du malais lembaga. Elles ne remontent d'ailleurs pas avant le début du Xvı ${ }^{e}$ siècle. Le terme est en fail déjà donné dans la liste des vocables malais recueillie en 1521 aux Moluques par Pigafetta : "al metalo : lumbaga ", écrit-il avant de nommer le fer (besi). On voit encore ici l'opposition fer/mélal (dans l'acception ancienne de ce dernier terme, dont on a déjà vu qu'il servait surtout à désigner les alliages du cuivre; il ne s'agit donc pas d'une erreur de Pigafetta, comme l'aflirme A. Bausani : "The first Italian-Malay Vocabulary by Antonio Pigafelta ", Easl and West, Xl/4, 1960, pp. 235, 243). Le Spraek ende woord boek de Frederick de Houtman, de la fin du Xvi ${ }^{e}$ siècle, confirme encore notre propos en glosant "tambagga " lout à la fois par "cuivre "et "métal " (éd. D. Lombard, Paris, 1969, p. 241 . 
On doit enfin ajouter que les notions d'alliage et de métal chimiquement pur, acquises par la chimie moderne, n'avaient alors pas cours.

L'acception générique de tembaga me scmble donc bien attestée et, par conséquent, on comprendra qu'il ait parfois servi à lui tout seul à désigner le laiton, lorsque la précision d'un qualificatif supplémentaire ne se faisait pas sentir.

Ce canon pris sur la galère atjihaise, qui n'est ni en fer forgé, ni en bronze, est donc sclon toute vraisemblance en laiton. La valeur considérable qui lui est attribuée par les Portugais peut-clle ĉtre seulement celle du laiton ? Vu la rareté du zinc dans le monde nousantarien (cf. infra), il est vraisemblable que le laiton ait été plus cher que le bronze. Mais on pcut aussi penser qu'il s'agissait d'un laiton auquel on avait ajouté une faible quantité d'or, autrement dit du tembaga suasa. On sait que l'usage de cet alliage était courant à Atjéh (1).

Quant à la provenance des métaux destinés à la fonte des canons, on a déjà vu (supra, p. 237) que les importations de cash chinois avaient pu fournir le cuivre nécessaire (sans compter l'exploitation du cuivre philippin). Pour les bronzes, l'approvisionnement en étain en péninsule malaise ne posait aucun problème. Pour les laitons, ce devait être plus difficile : les recherches géologiques n'ont pas, à ma connaissance, révélé de gisements de calamine dans le monde nousantarien (2). Mais cette difficulté devait être aisément surmontée par l'importation des matières premières : la calamine était extraite en Inde, au Tonkin et en Chine, toutes régions qui, avec la Perse, produisaient et utilisaient le laiton à grande échelle dès le premier millénaire. Cet alliage circulait sur la route maritime transasiatique : on le trouvait

(1) D. Lombard, I.e sullanal d'Atjéh au temps d'Iskandar Muda, Paris, 1967, pp. 50, 87, 131-135, 141, 151.

(2) Le zinc n'existe pas à l'étal nalif. Ses minerais les plus courants sont la calamine (carbonate nalurel de zinc) el la blende (sulfure de zinc). Seule la calamine, qui était directement fondue dans un fourneau avec cuivre et carbone pour l'oblention du lailon, était traditionncllement exploitée, la blende n'ayant élé reconnue que récemment (R. J. Forbes, Melallurgy in Antiquity, Leiden, 1950, pp. 272-273). Or on n'a trouvé que quelques faibles gisemenls de blende en péninsule malaise (E. $\mathrm{S}$. Wilbourn, "A list of minerals found in British Malaya ", .Il. Malayan Branch, Royal Asialic Soc., III/3, 1925, p. 93); j'ai aussi trouvé mention d'un gisement de minerai de zinc non précisé à Sumatra, dans les hautes terres de Padang (O. Collel, Terres et peuples de Sumatra, Amsterdam, 1925, p. 31 ; Lê Thanh Khôi, L'économie de l'Asie du sud-est, Paris, 1964, p. 72). Manocl Godinho de Eredia, qui écrivait à Malaka au début du xvir e siècle, est cerlainement le premier autcur européen à tenter de décrire en détail les productions minières du monde nousantarien dans son Informação da Aurea Chersoneso (publice pour la première fois par A. L. Caminha a Iisbonne en 1807 ; cf. aussi sa traduction anglaise par Mills in : J. Malayan Branch, Royal Asiatic Soc., VIII/1, 1930). Mais ses conmaissunces minér'dlogiques y apparaissent pour le moins confuses : c'est ainsi qu'il cile un nombre considérable de "mines" diverses là où il ne faut certainement voir que des centres de réexportation ou de produclion artisanale : il signale ainsi à Bornco, à Makasar el à Timor de nombreuses el richissimes "mines " de lembaga (suasa), de cuivre el d' arame "(mot portugais qui designail alors un alliage obtenu en fondanl du cuivre et de la calamine, soit précisćment du lailon, selon la méthode traditionnelle). 11 abandonne d'ailleurs de lui-même ces descriptions dithyrambiques dans un ouvrage postéricur (1613), plus achevé, dans lequel on ne trouve plus que du lembaya à Timor (manuscril édité el traduit pour la première fois par L. Janssen, Malaca, l'Inde méridionale et le Calhay, Bruxelles, 1881-1882; "se acha muyto ouro e tombaga em Timor" y est malheureusement traduil par "on trouve beaucoup d'or à Tombaja dans l'île de Trimor ", pp. 40, 46 ; cf. aussi la lraduction, correcte, de Mills, ibid., p. 51). 
par exemple dans les produits amenés de Perse en Chine en 590 et 739 (1). En Asie du sud-est, le zinc - en composition dans les laitons et parfois, en faible proportion. dans les bronzes - tient déjà une place appréciable dans la culture du Transbassac, comme dans celle de la région de Kedalı, dans les cinq ou six premiers siècles de l'ère chrétienne (2). Les sources chinoises font épisodiquement mention de laiton en Asic du sud-est sans qu'il soit possible de déterminer s'il s'agit d'une production locale ou d'une réexportation. Dans sa notice sur le Dan-mei-liu, pays situé sur la péninsule malaise - au nord de l'isthme de Kra, semble-t-il (3) -, l'histoire des Song indique que l'on y trouve du laiton et une ambassade de ce même pays en porte en 1001 en tribut à la Chine, en même temps qu'un alliage multiple d'étain, de plomb et de zinc (4). Le laiton (lou) est encore cité à propos de la composition des monnaics ayant cours à Java dans le Lingwai daida de 1178 (5). On sait par ailleurs que les cash chinois importés en grande quantité en Asie du sud-est n'étaient pas exclusivement faits de cuivre, mais souvenl aussi de laitons de proportions variables (en particulier sous les Qing) ou même (sous les Ming) de zinc pur (toutenage) (6). Ils ont donc pu servir aussi de matière première à la fonte de canons en laiton.

Si l'on ajoute à l'ensemble de ces données le fait que l'usage de vaisselle ct de bijoux en tembaga est largement attesté par les textes et que le travail du laiton à la cire perdue est traditionnel dans l'Archipel (7), on comprend mieux l'existence de pièces d'artillerie fondues dans cet alliage.

Sont-elles exceptionnelles dans la production locale? La relative rareté du zinc tendrait à le faire eroire, mais des analyses effectuées sur des collections importantes pourront seules le confirmer.

(1) Needham, op. cit., pp. 198 sq. ; Forbes, op. cil., pp. 279 sq.

(2) I. Malleret, L'archéologie du Della du Mékong, Paris, 1969, vol. IJ, pp. 250, 358, 366. H. G. Quaritch Wales, "Archaeological Researches in Ancient Indian Colonization in Malaya », Jl. Malayan Br., Royal Asialic Soc., XVIII/1, 1940, p. 47. Si l'on se range aux conclusions d' $\Lambda$. Lamb, le site de Kedah serait plus tardif ("Report on the excavation and reconstruction of Chandi Bukit Batu Pahat, Central Kedah ", Federation Museums Journal, V, 1960, pp. 104-105).

(3) P. Wheatley, The Golden Khersonese, Kuala Lumpur, 1961, p. 66.

(4) Necdham, op. cil., pp. 201, 215-217, qui fait référence à ce pays de Dan-mei-liu du Song shi (j. 489, 24a) et à son ambassade, qu'il dale à lort de l'an 1000. Mais, à propos de ce même Dan-mei-liu, il cite le Zhufan zhi (de 1225; trad. Hirth et Rockhill, St. Petersbourg, 1911, pp. 62, 67) et le Daoyi zhilue (de 1350; trad. Rockhill, T'oung-pao, XVI/1, 1915, pp. 123-124); or il s'agit dans ces deux textes d'un autre pays, le Dan-ma-ling (Tảmbralinga) situé lui aussi sur la péninsule malaise, mais plus au sud, à Ligor (Wheatley, op. cil., p. 67 ; O. W. Wolters, "Tümbralinga ", Bull. School of Oriental and African Sludies, XXI, 1958, p. 587-607). En ce qui concerne ce deuxième pays, ces sources ne mentionnent pas le laiton; seul le Daoyi zhilue fait référence à un mélal, lo bai $x i$ 白鹤 qui, d'après Needham (op).cil., p. 215), serait un alliage mulliple de zinc, d'étain el de plomb ou peut-être même du zinc métallique (Rockhill traduil à lort par "superior tin ").

(5) Ed. du IIebu zuzhai congshu, j. 2, 12a. Le passage est repris dans le Zhufan zhi. Hirth et Rockhill (p. 78) traduisent erronément lou par "white copper". Dans leur commentaire (p. 81) ils rappellent que Crawfurd a trouvé au xixe siècle des monnaies javanaises en laiton.

(6) Needham, op. cit., pp. 210-211.

(7) Encyclopaedie van Nederlandsch Indië, s. v. metaalbewerking, Koperenmessing ( $2 \mathrm{e}$ éd., vol. II, p. 716); J. E. Jasper et Mas Pirngadie, De Inlandsche Kunsinijverheid in Nederlandsch-Indië; De beiverking van niel-edele metalen, vol. V, Den Haag, 1930, p. 9 sq. 
Planche I
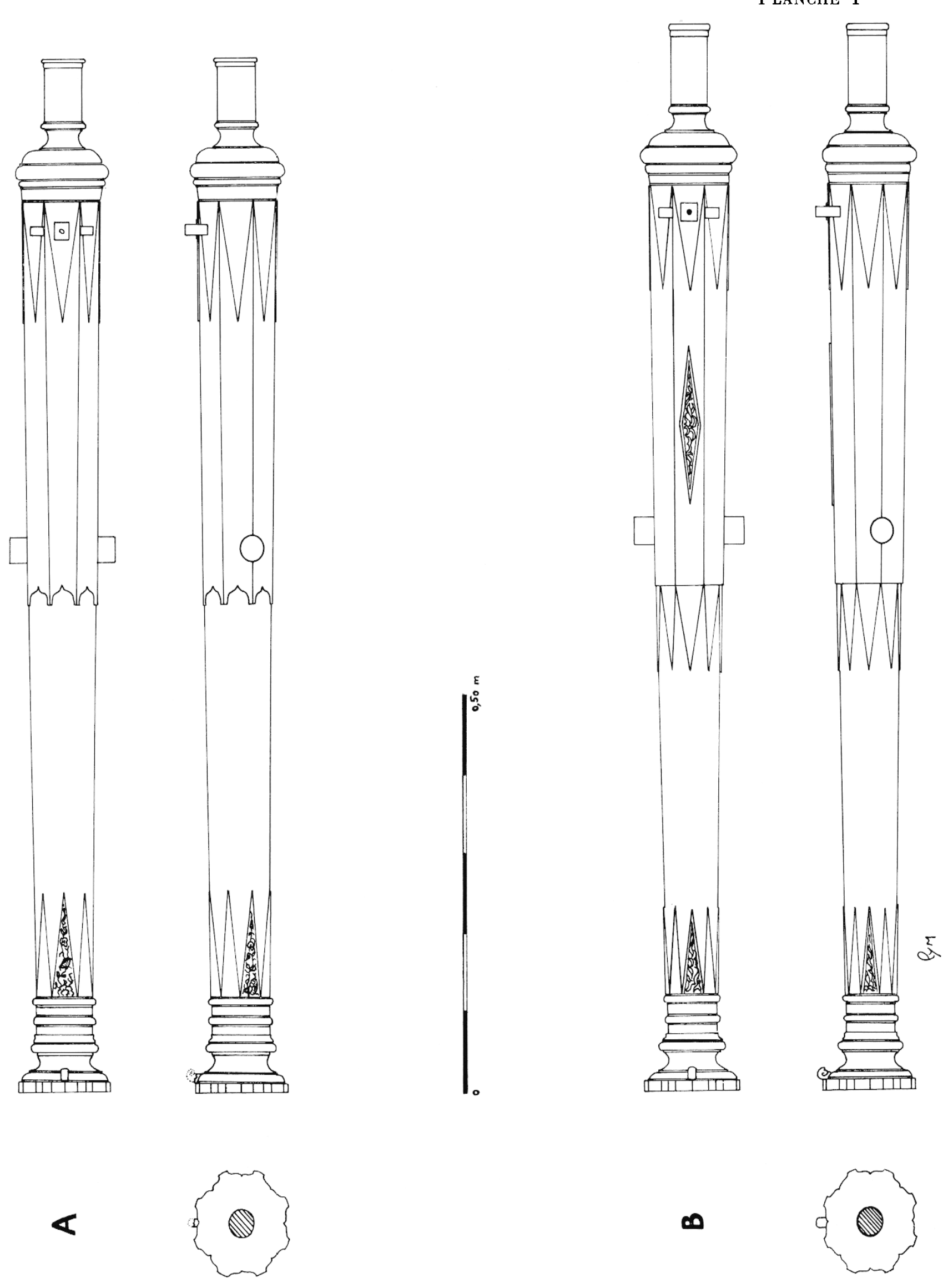

Pièces $A$ et $B$. 
Planche II
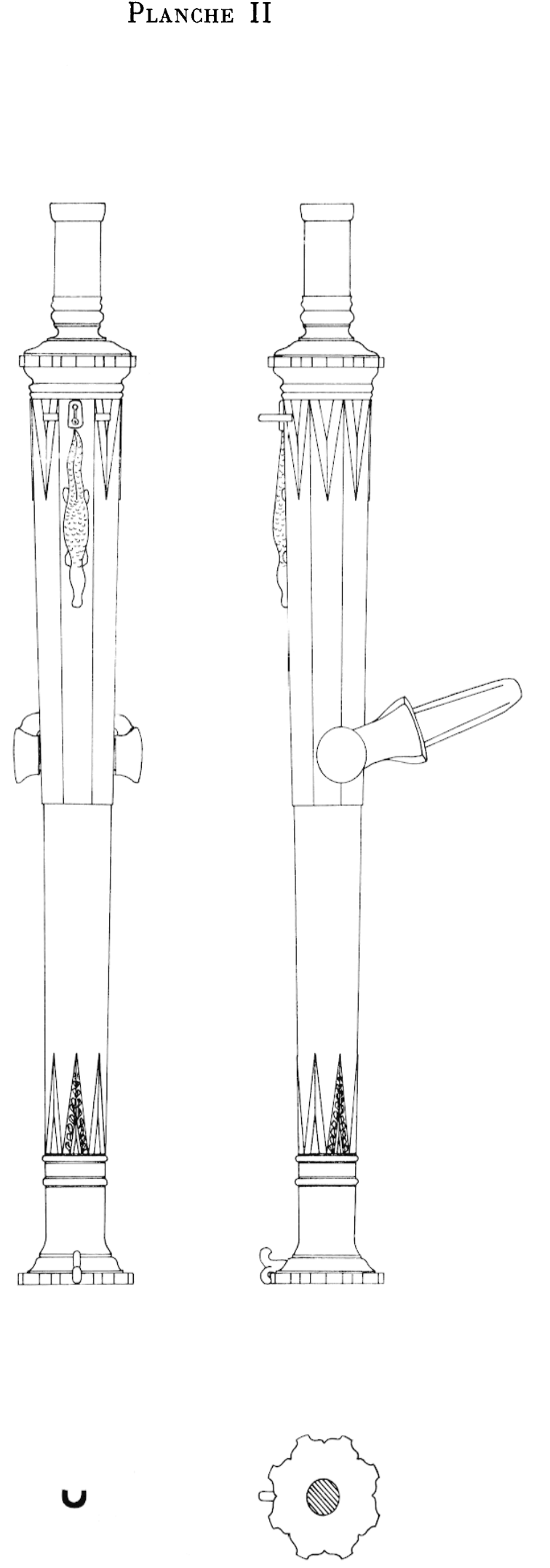
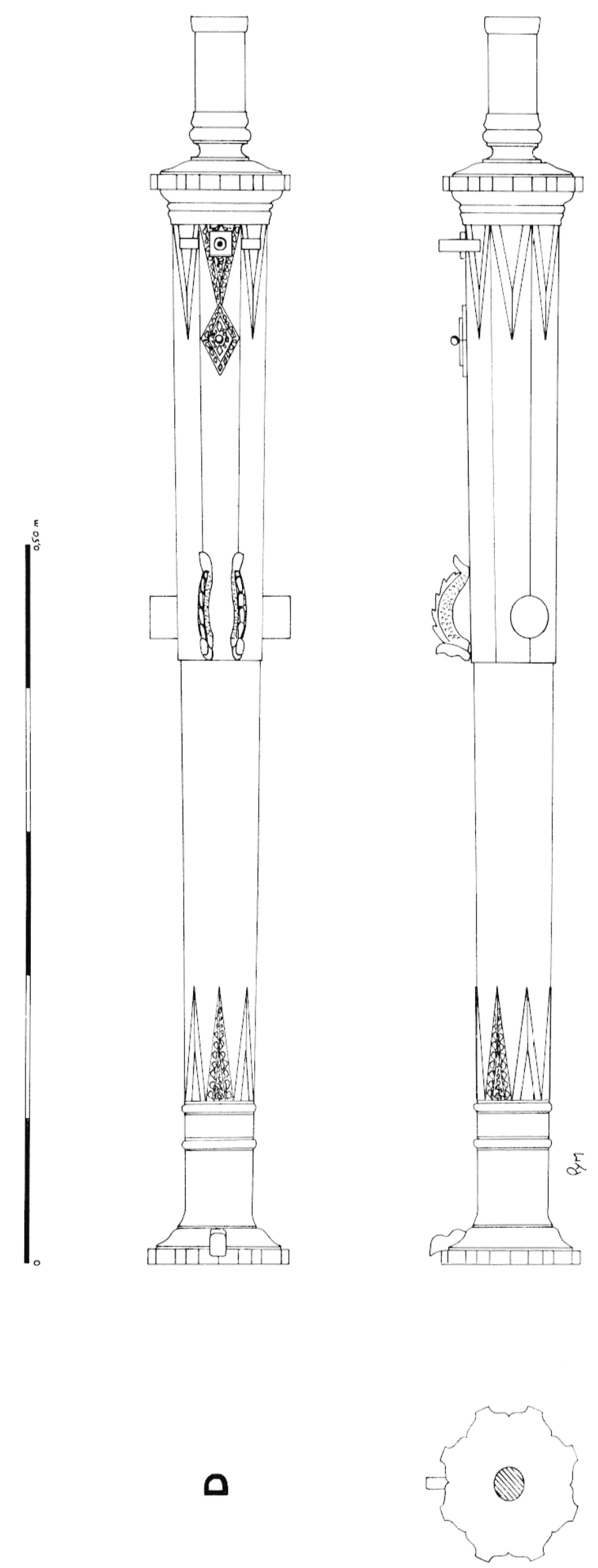

Pièces G et D. 

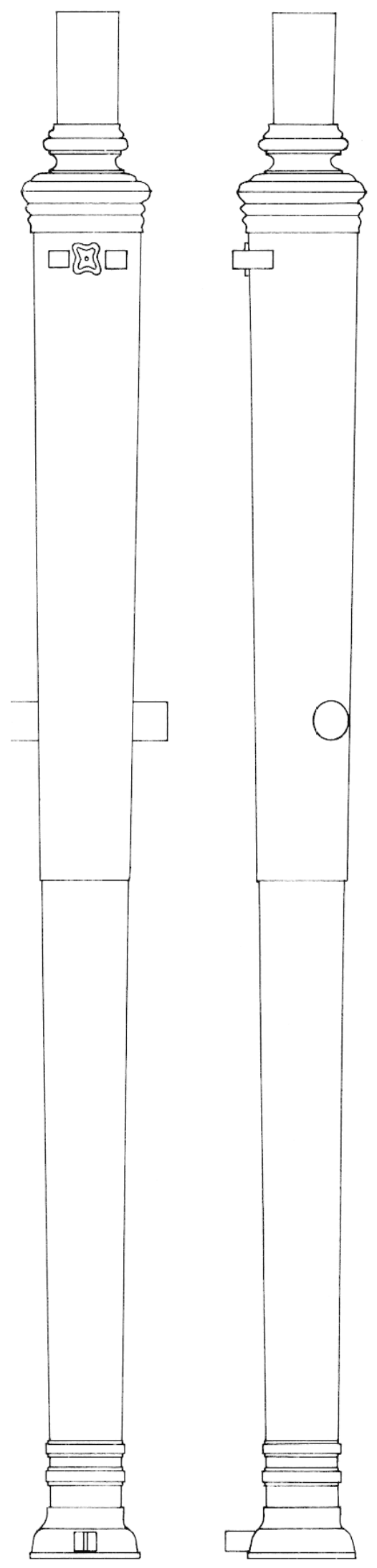

()

Planche III
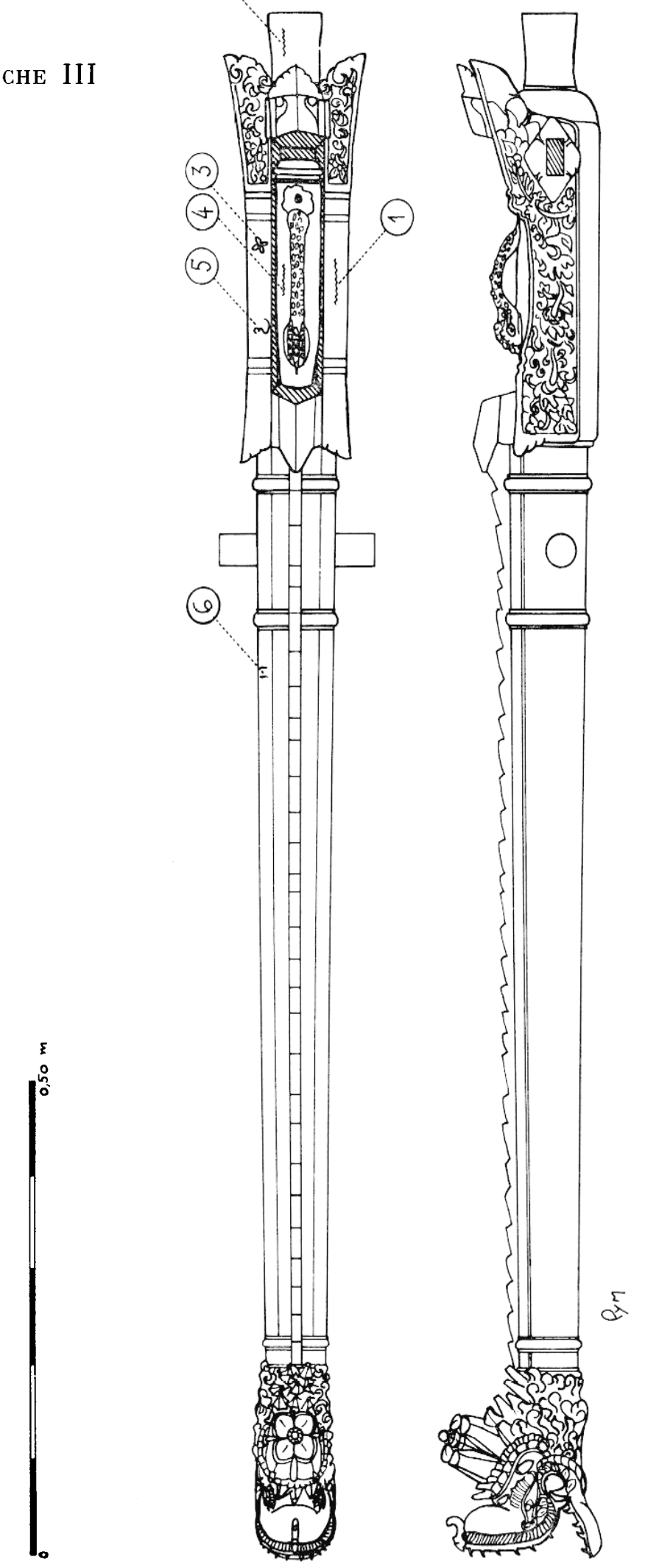

진

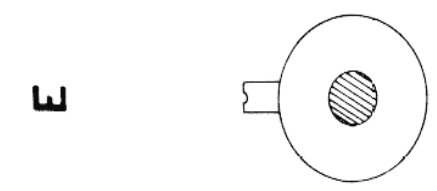




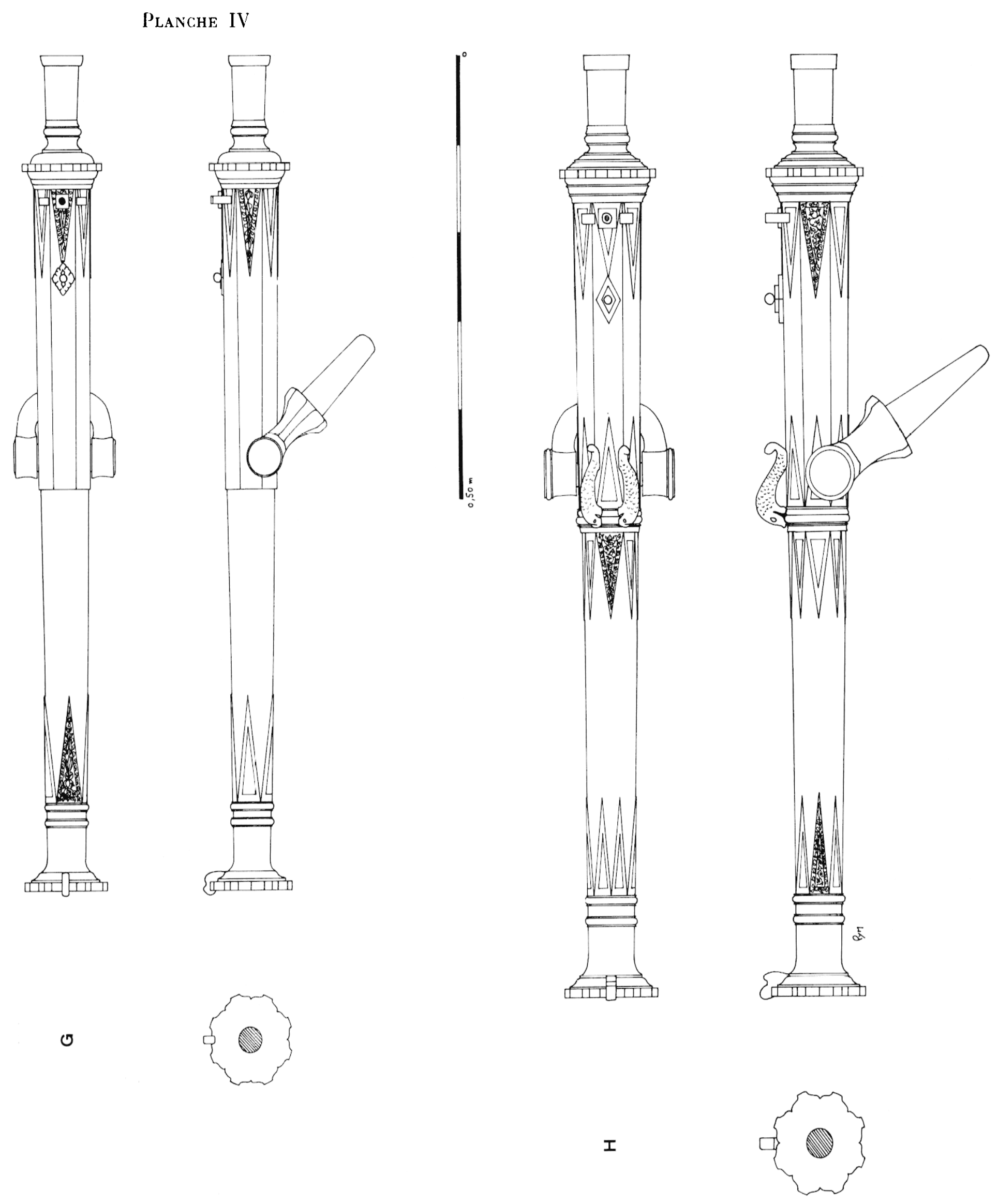

Pièces $\mathrm{G}$ ct $\mathrm{H}$. 

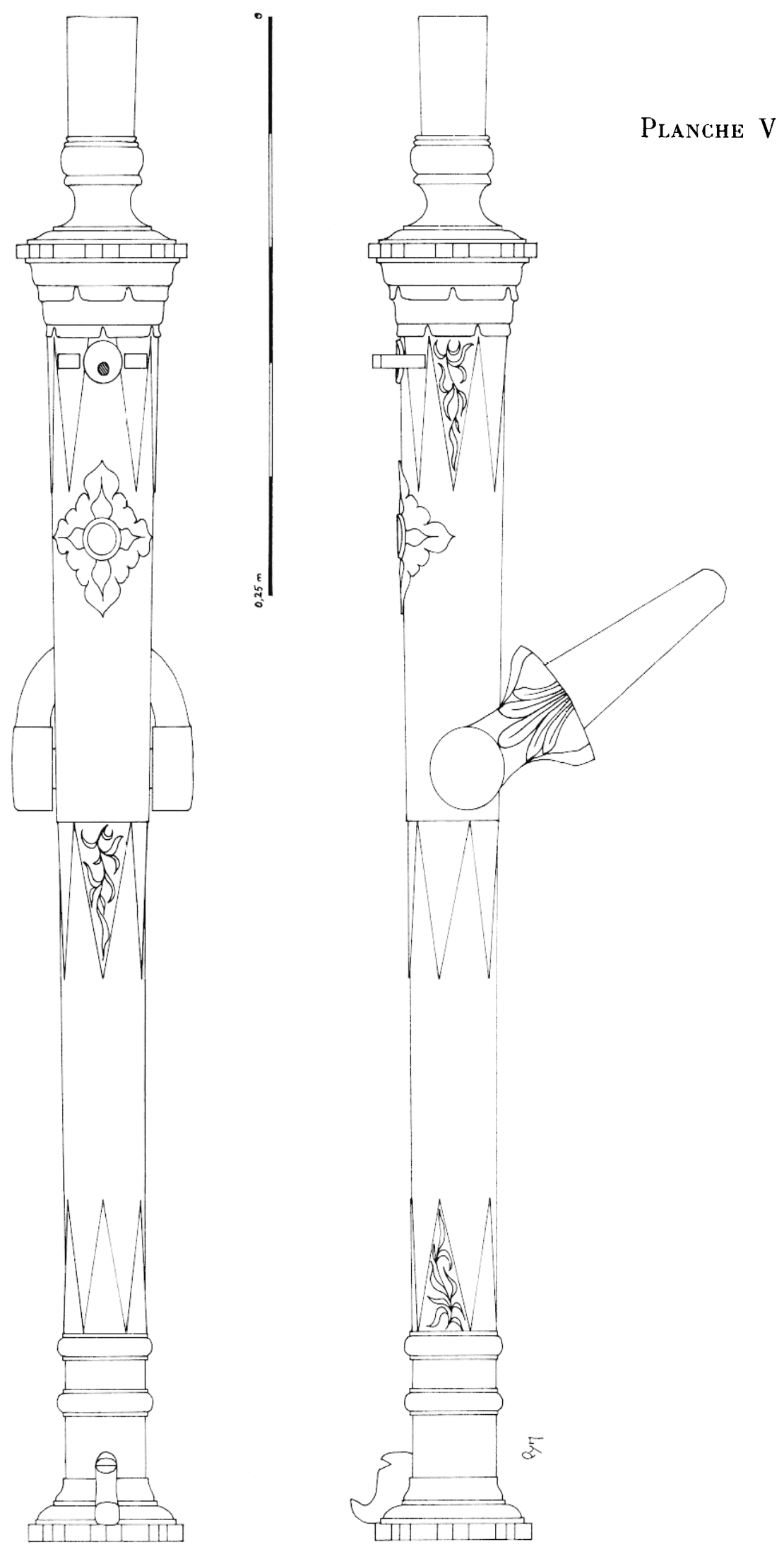

Pièce I.

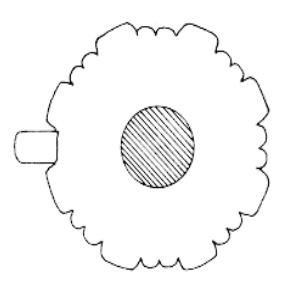


Planche VI

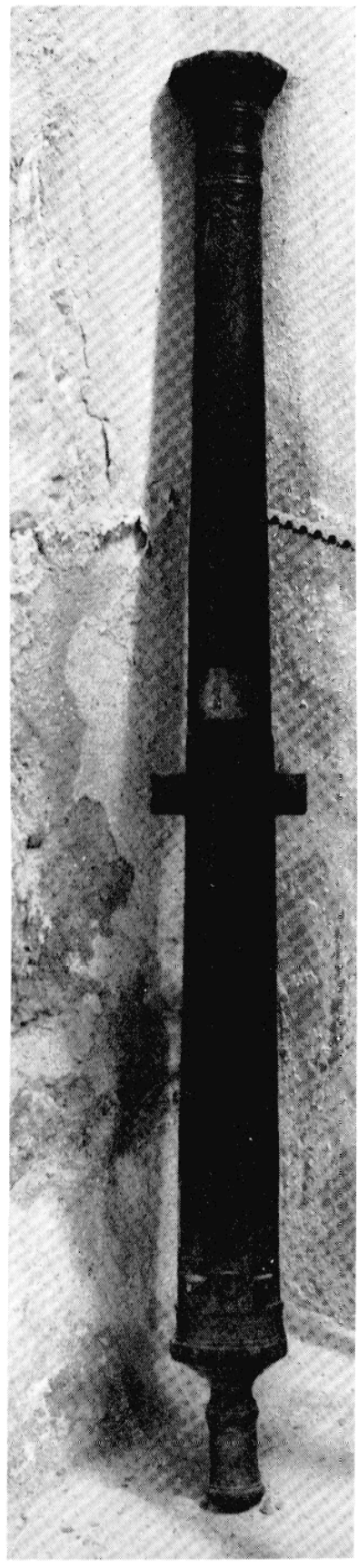

No I. Pièce $A$

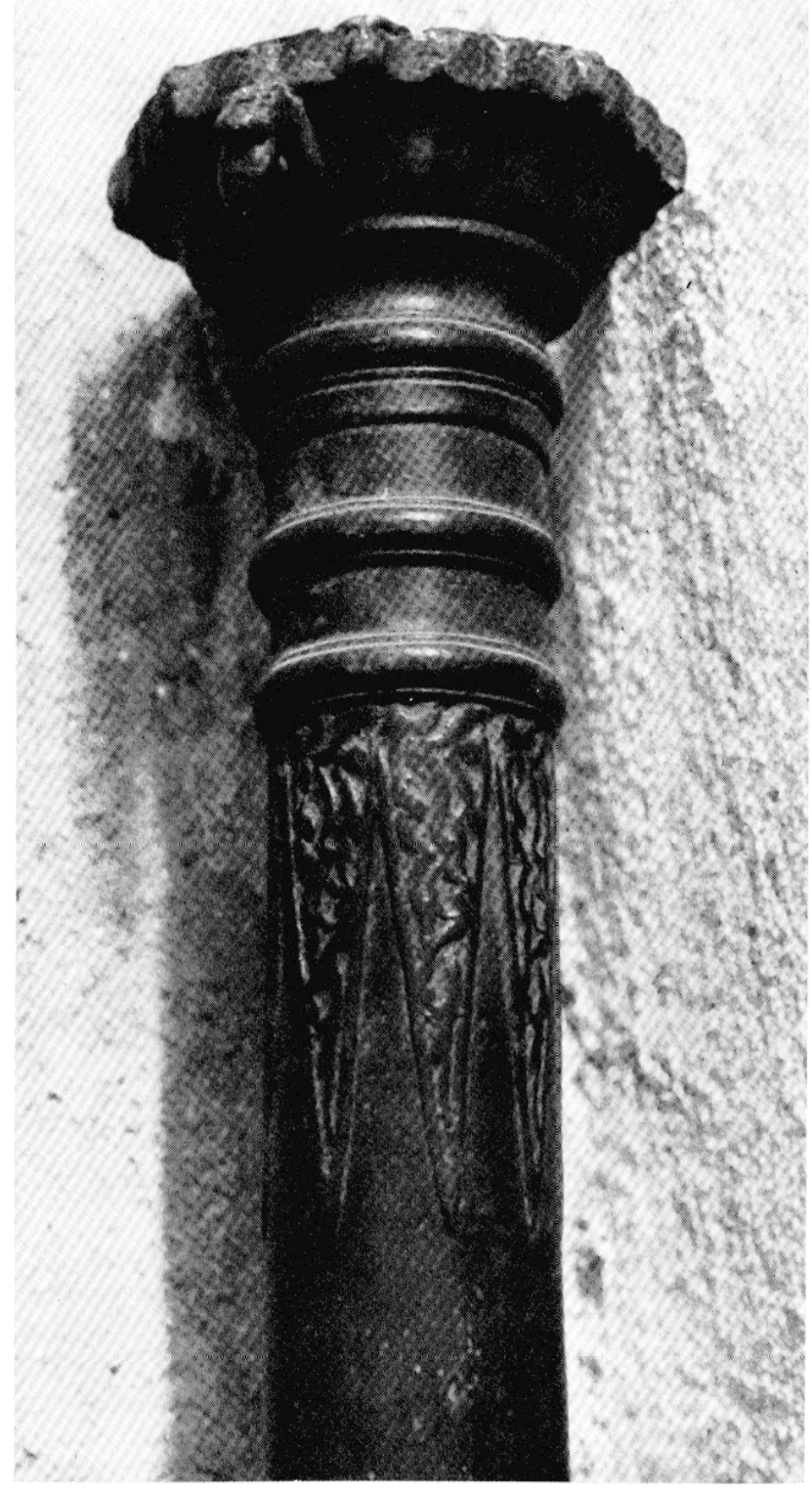

No 2. Piece B. Détail de la bouche.

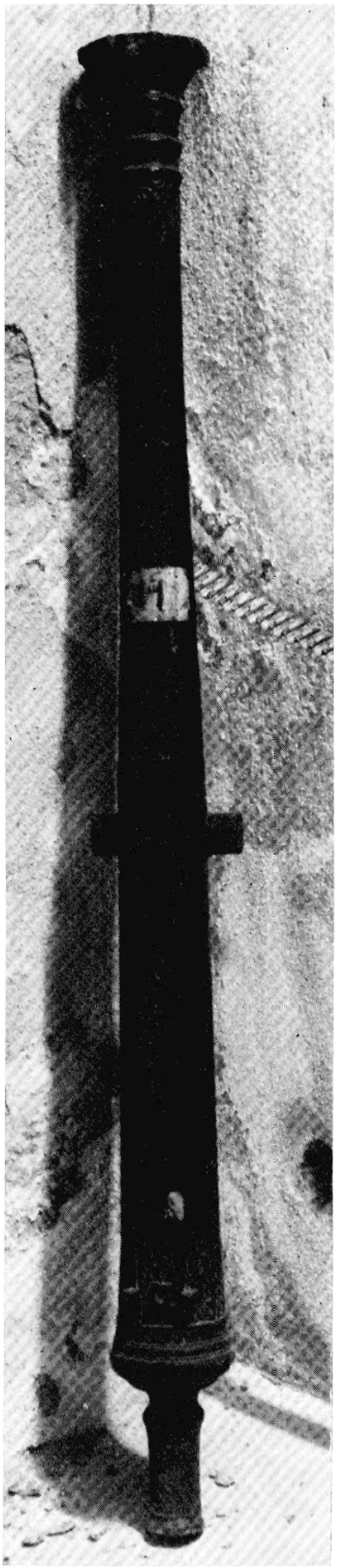

$\mathrm{N}^{\circ}$ 3. Pièce B. 


\section{PlaAnche VII}

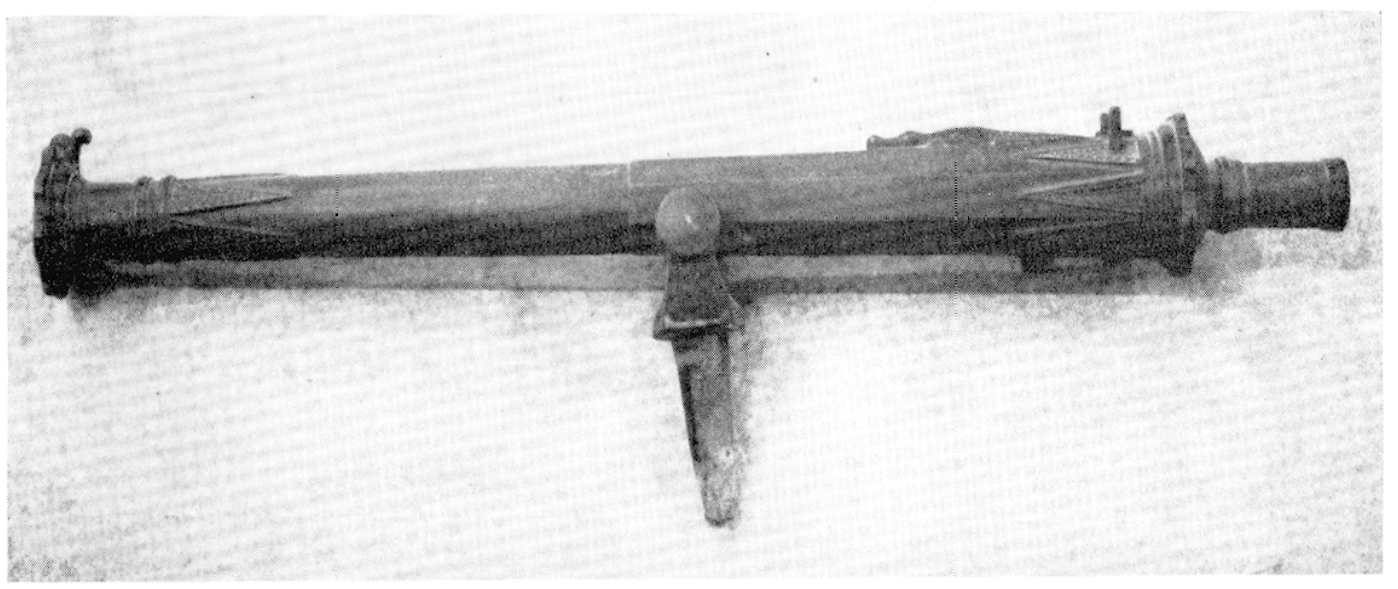

No 1. Pièce C.

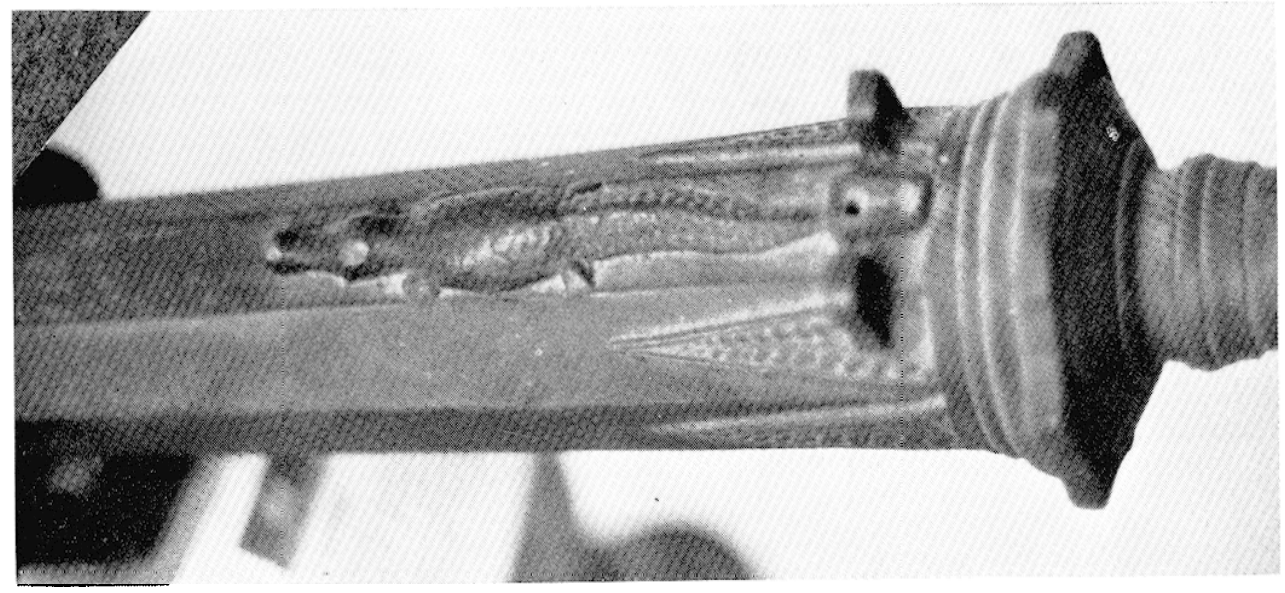

No 2. Pièce C. Délail de la culasse.

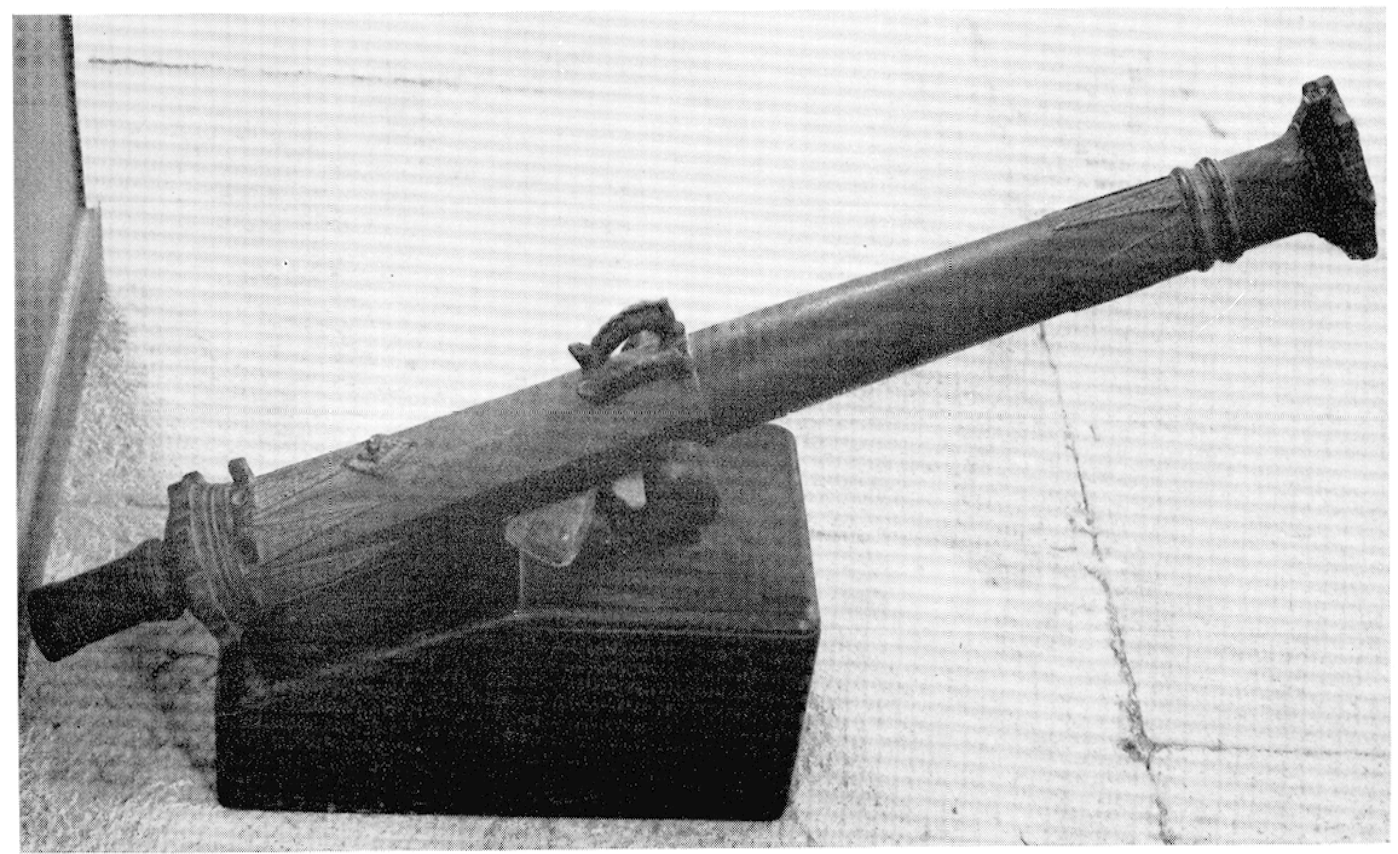

No 3. Pic̀ce D.

$$
17-1
$$


Planche VIII

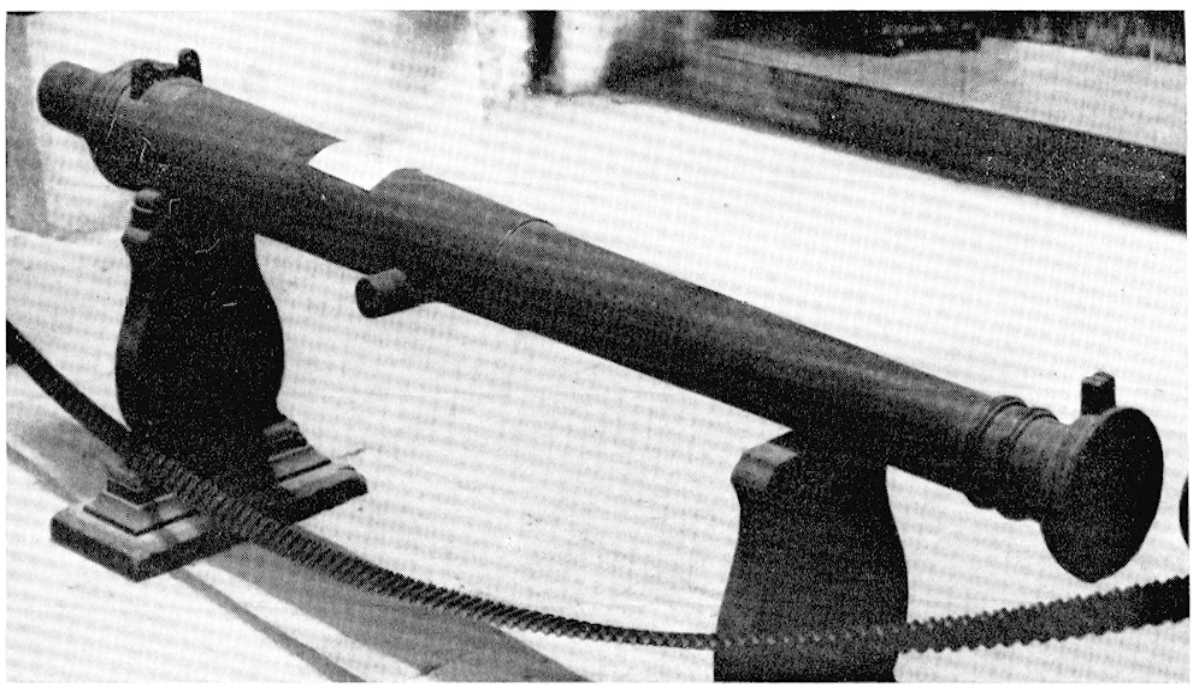

No 1. Pièce E

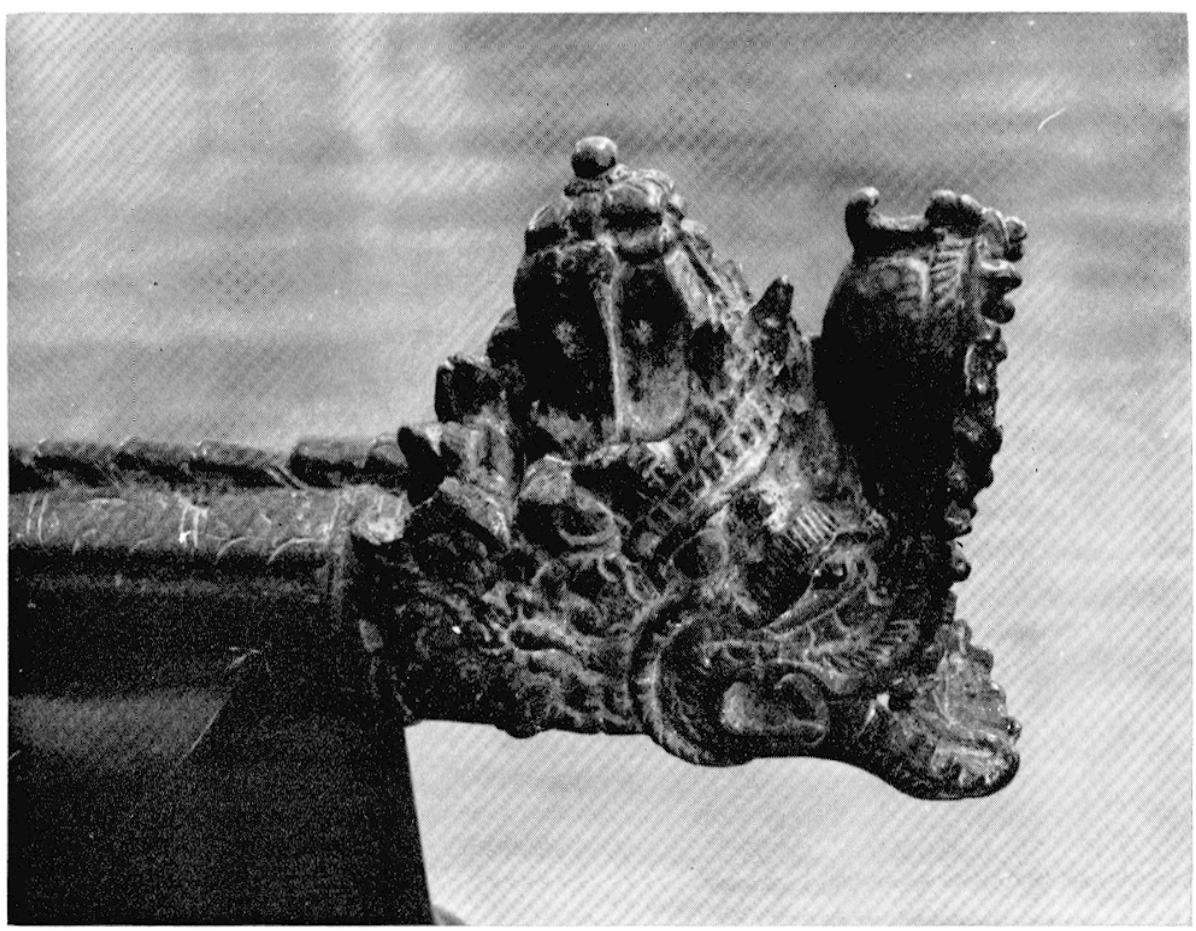

No 2. Piece F. Détail de la bouche.

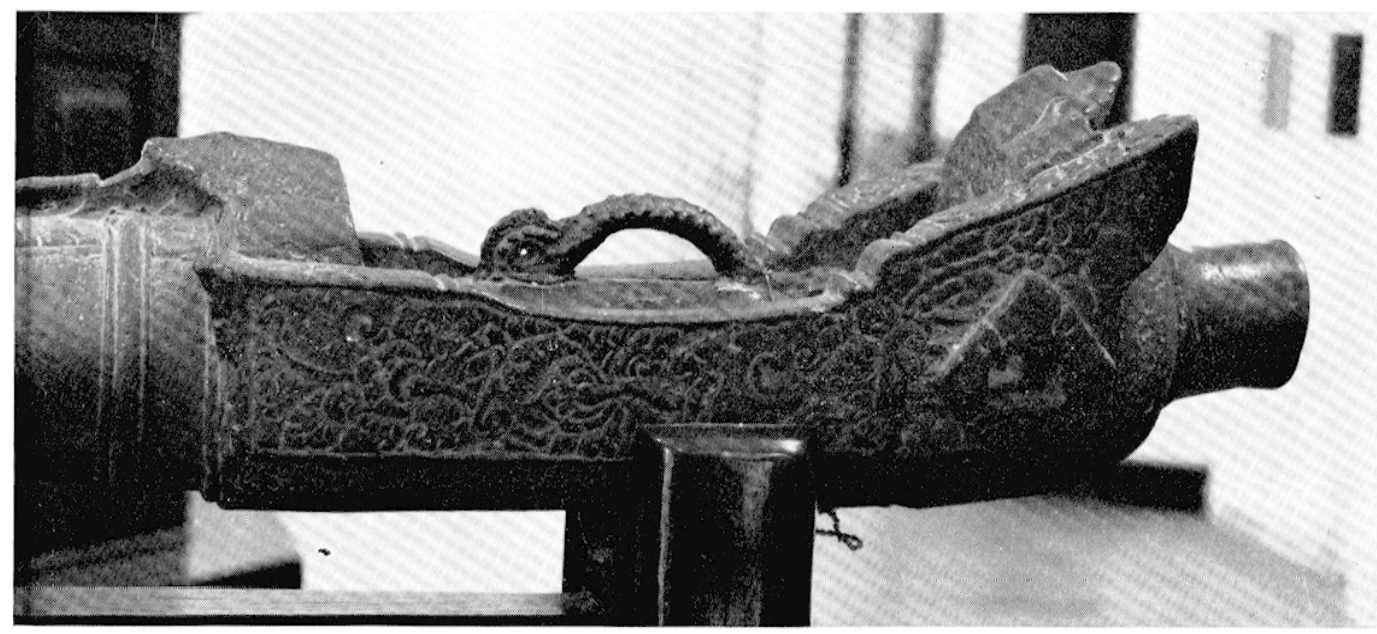

No 3. Pièce F. Détail de la culasse et boîte. 


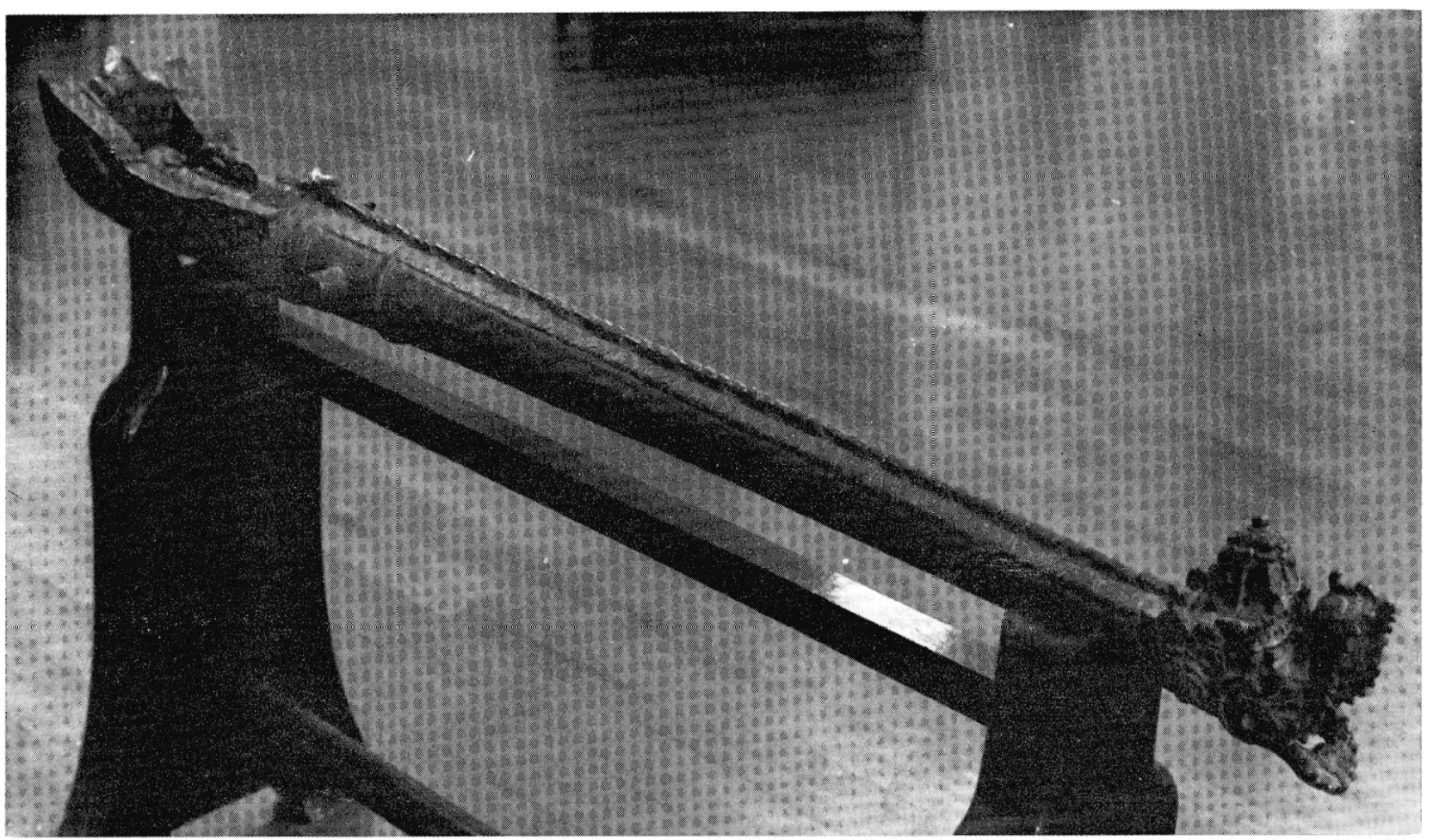

No 1. Pièce F.

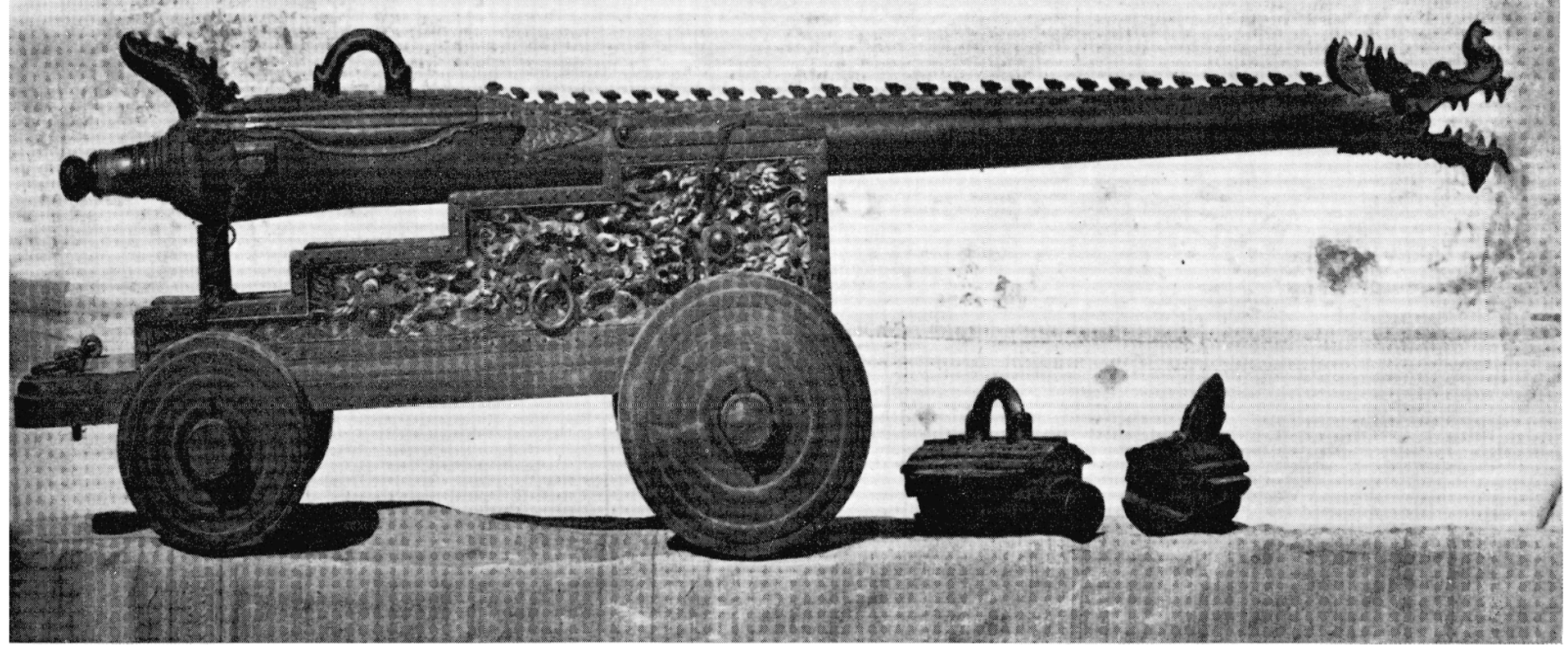

No 2. Pièce viêtnamienne de Châu-đốc. 


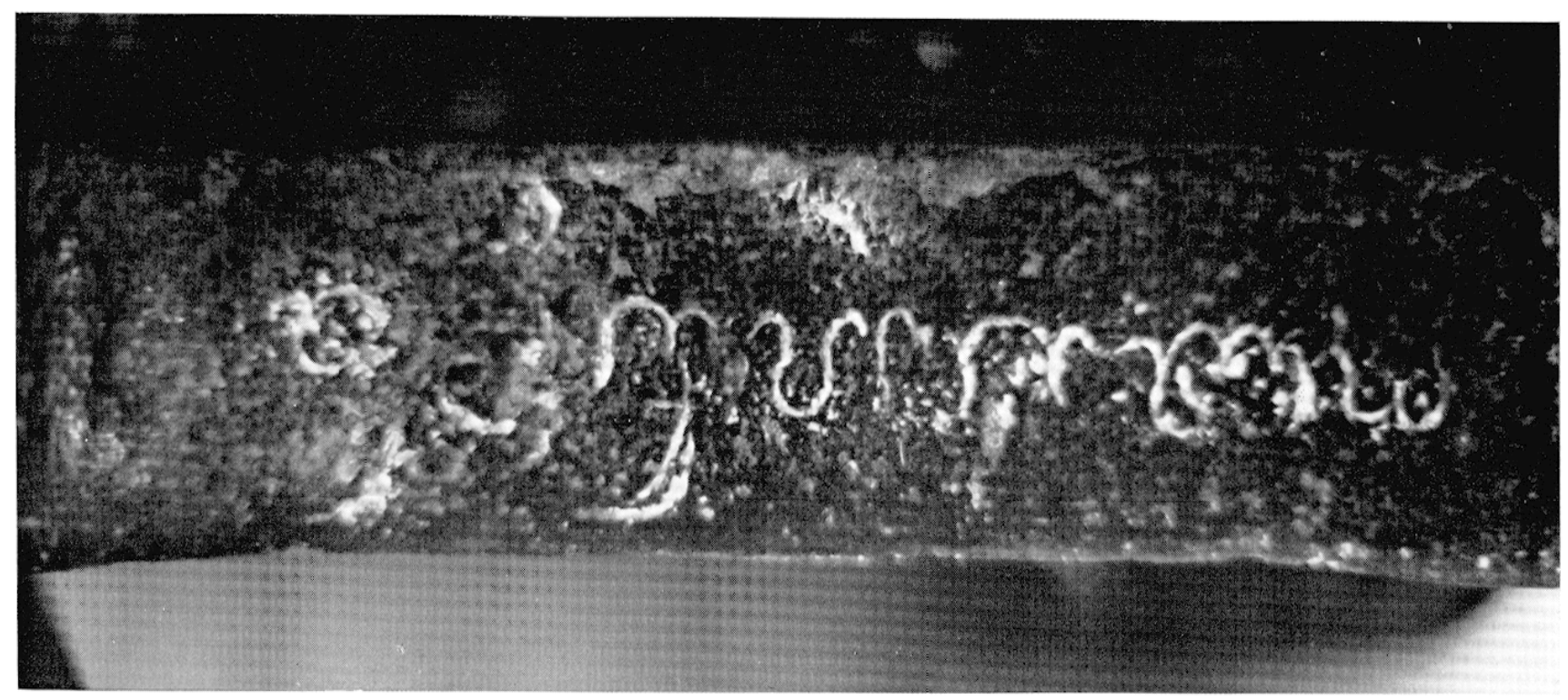

No 1. Pièce F. Inscription no 1 .

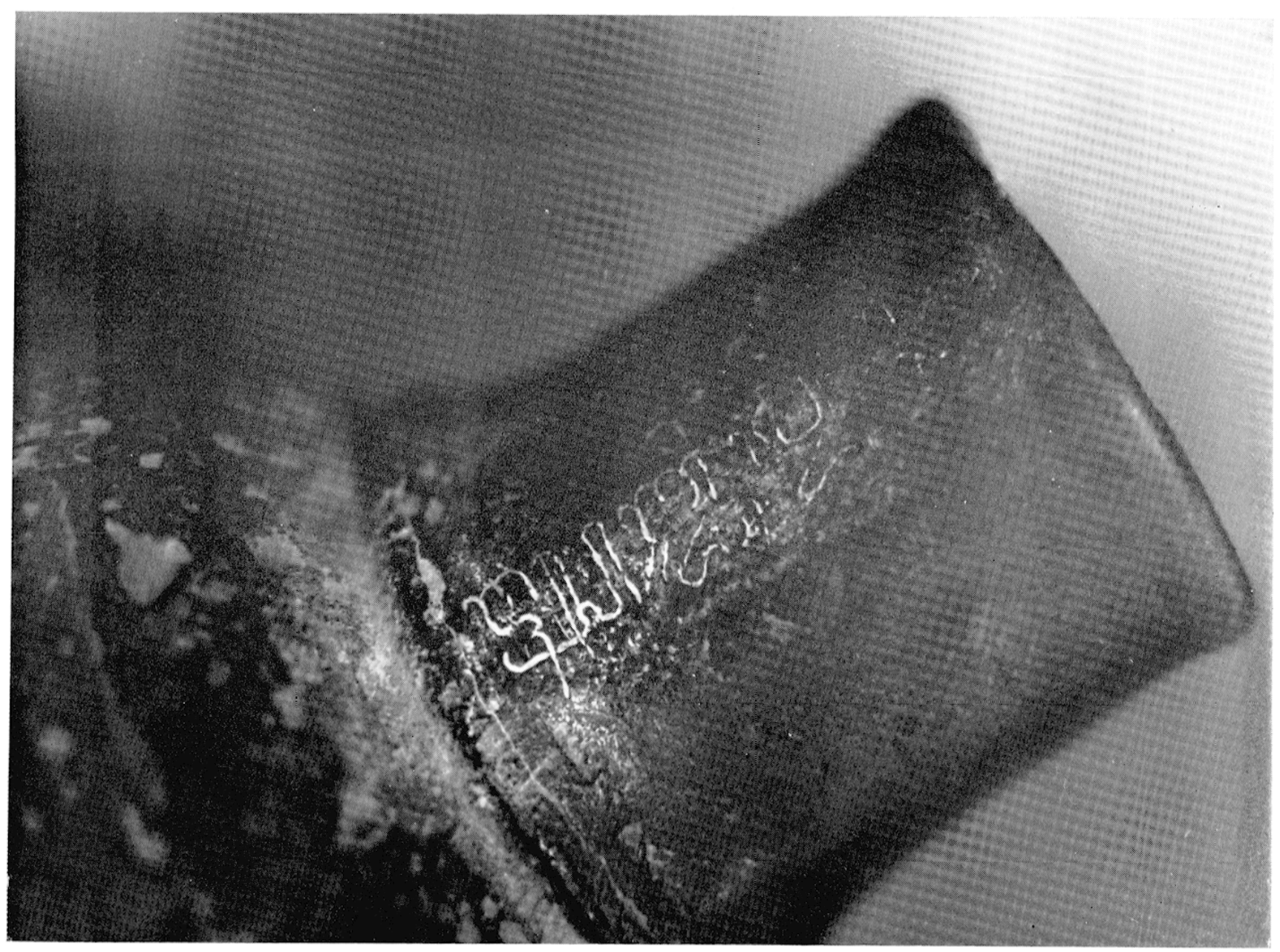

No 2. Pièce F. Inscription $n^{\circ} 2$. 


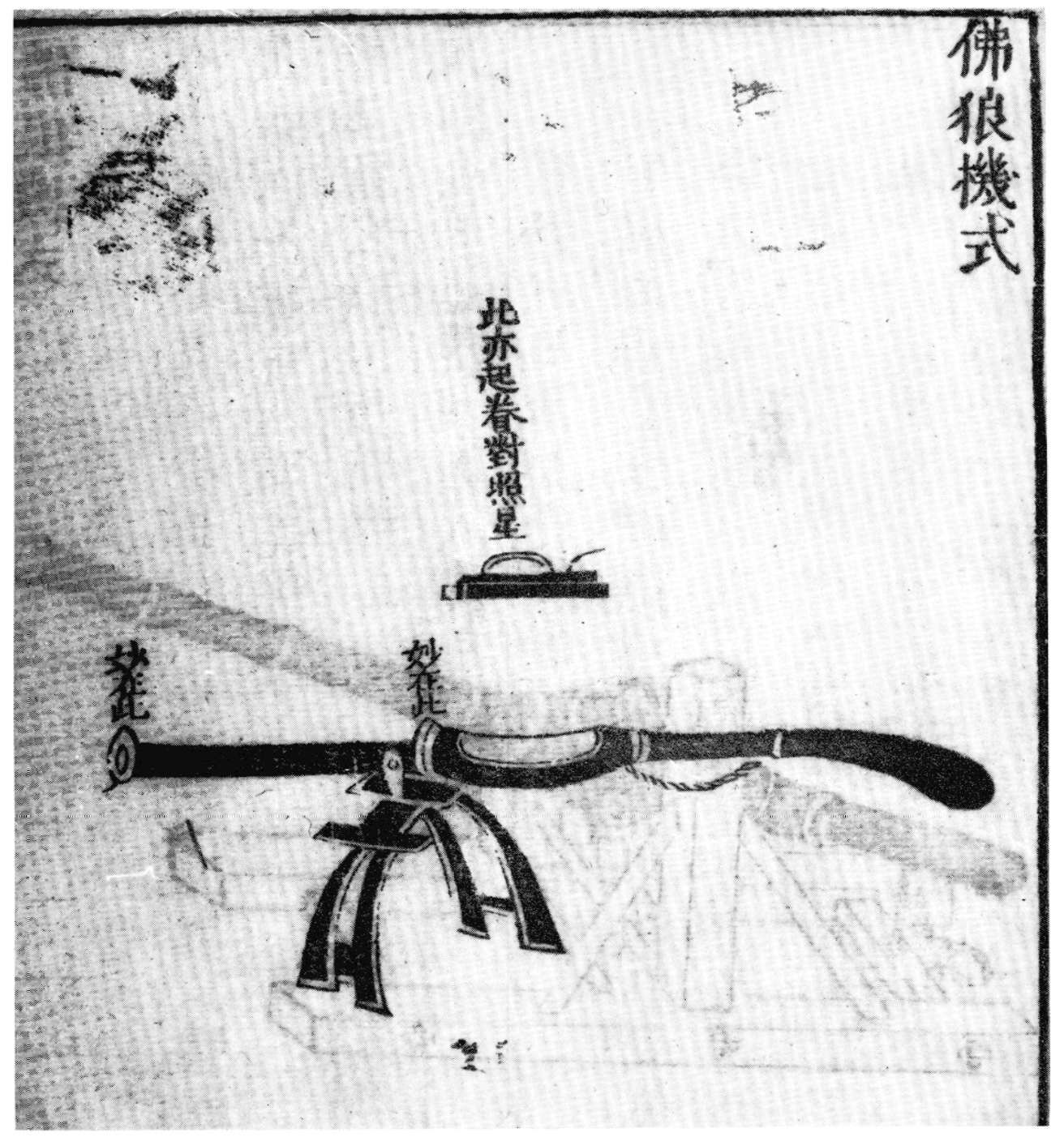

$\mathrm{N}^{\circ}$ 1. Canon à boîte fo lang $j i$.

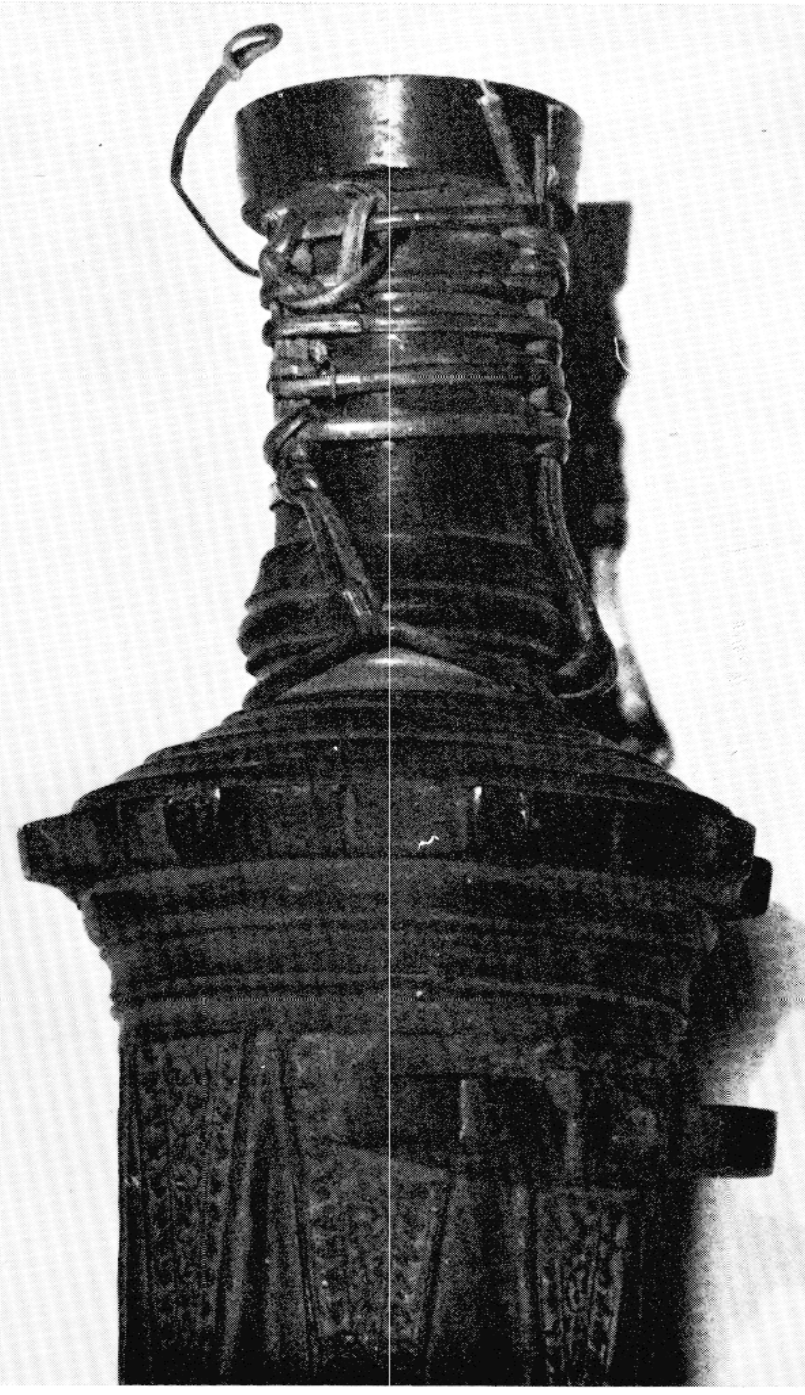

No 2. Pièce H. Bouton de culasse. 


\section{Planche XII}

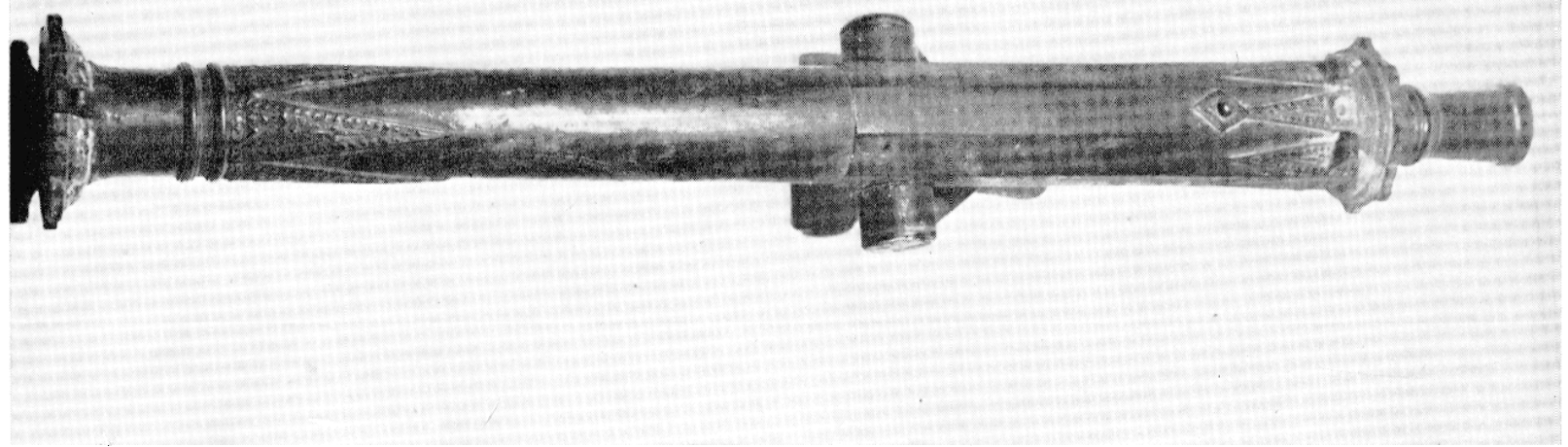

No 1. Pièce G.

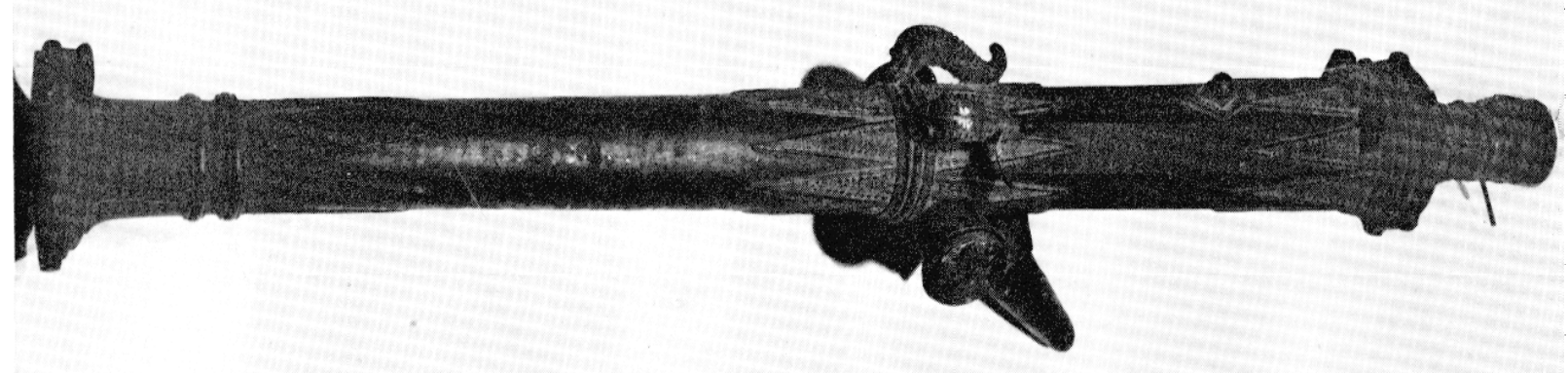

No 2. Pièce $H$.

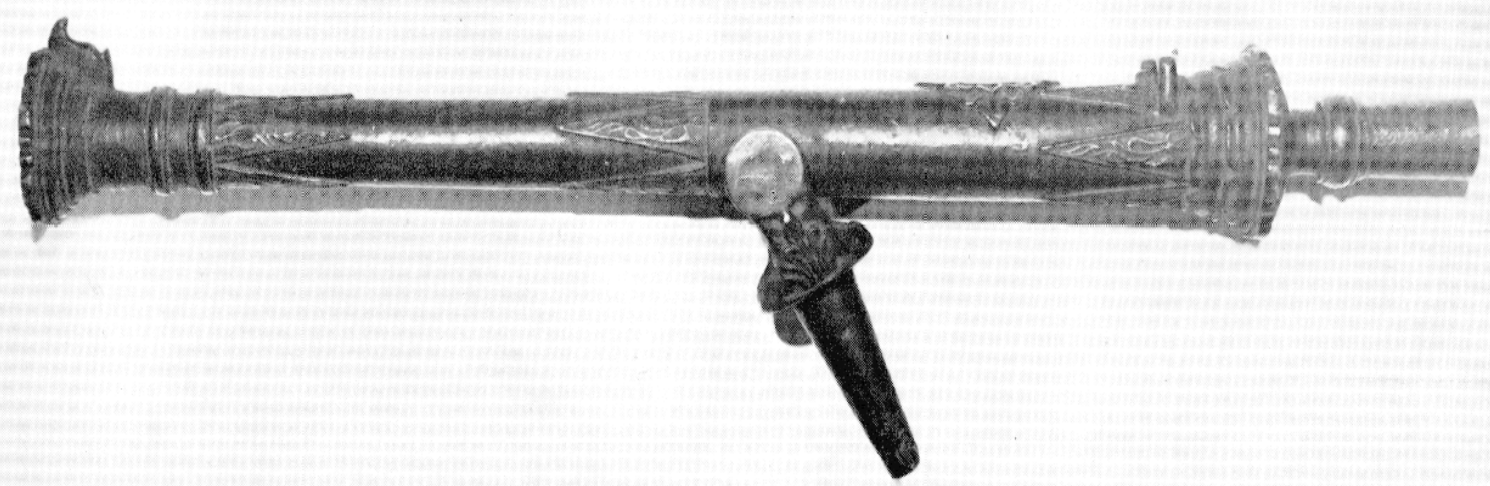

No 3. Pièce I. 
Planche XIII

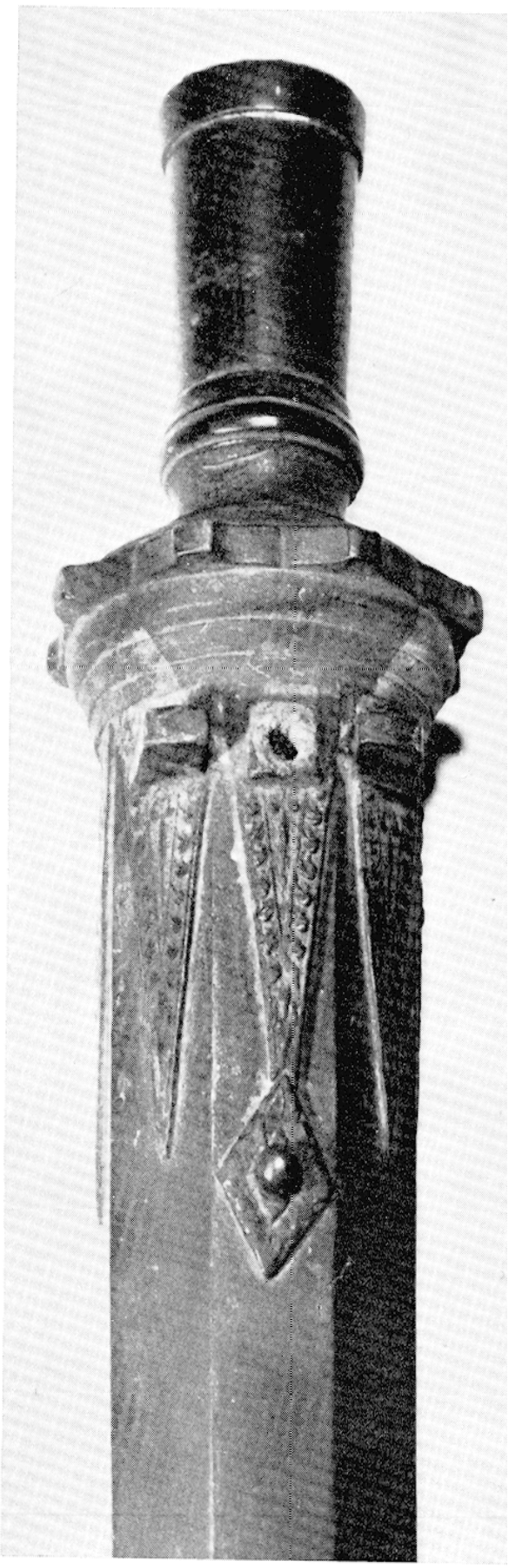

No 1. Pièce G. Détail de la culasse.

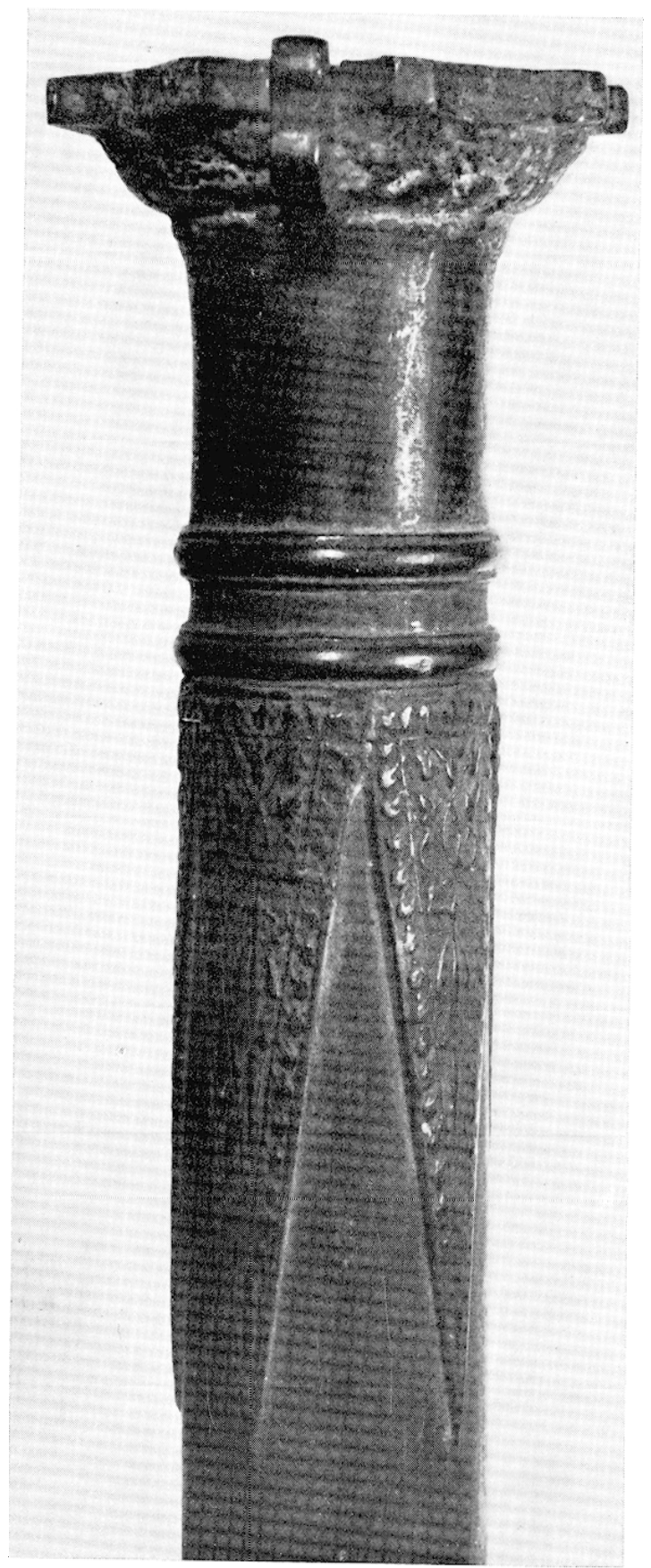

No 2. Pièce G. Détail de la bouche. 
Planche XIV

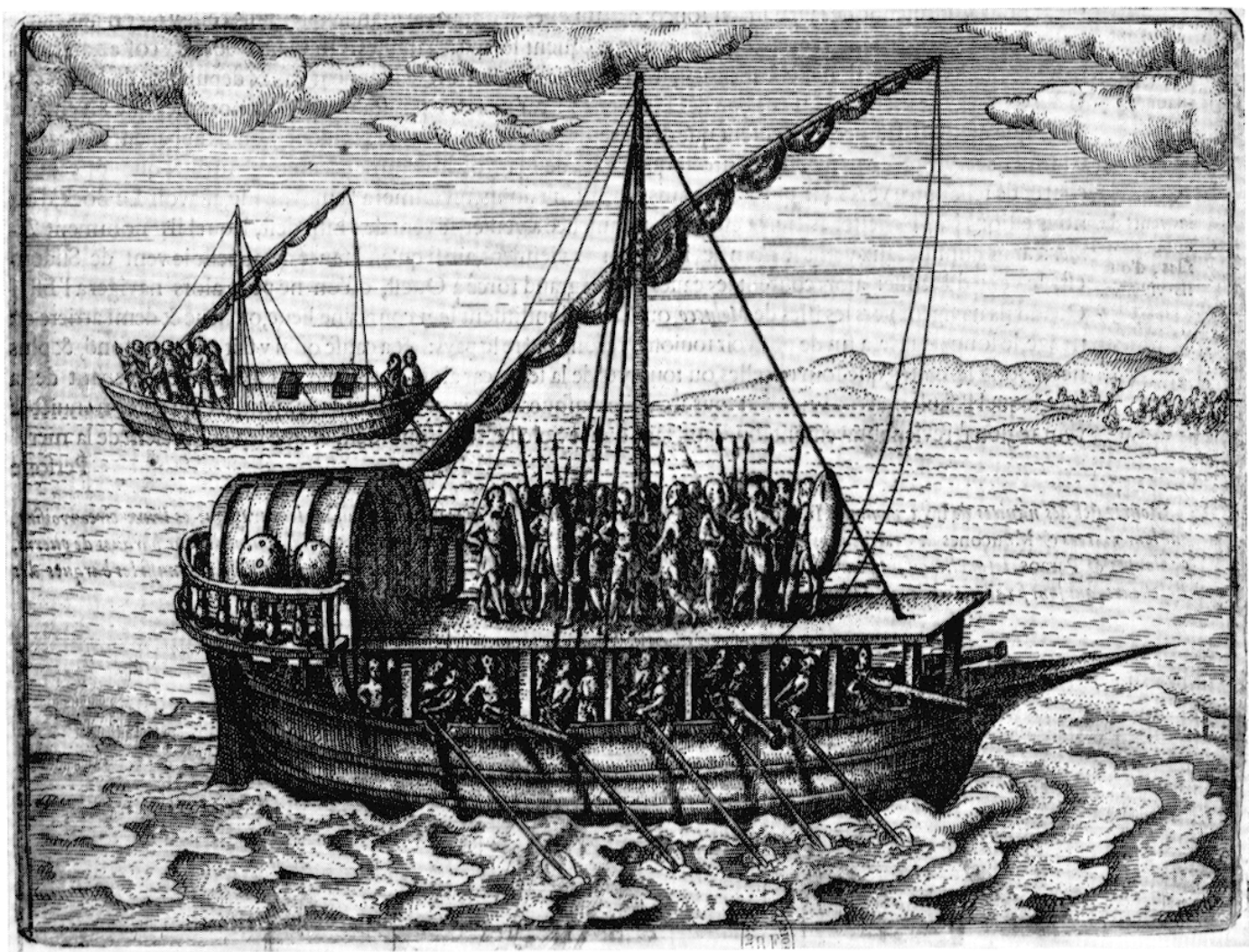

No 1. "Fuste" de Banten, 1598.

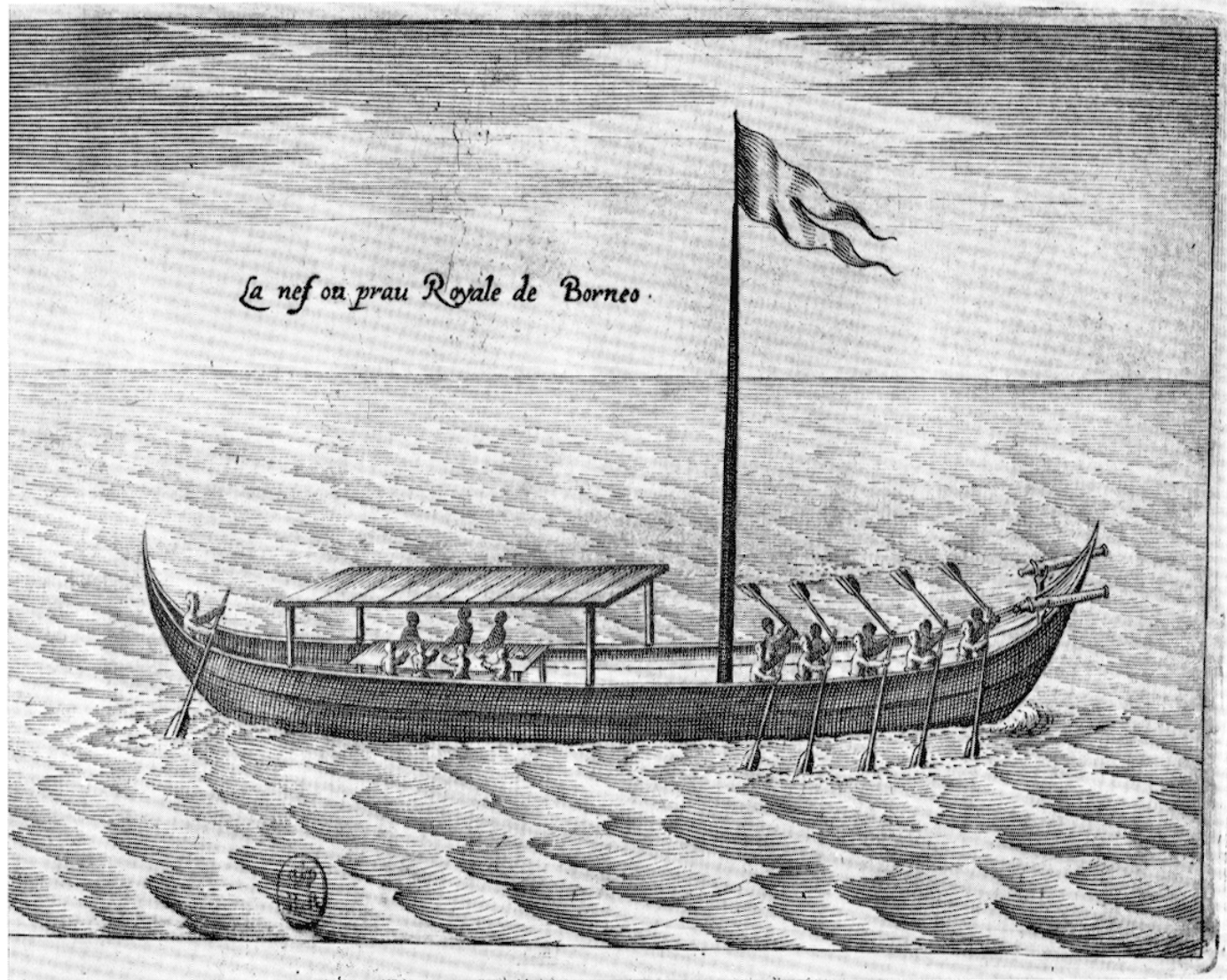

No 2. Perahu de Brunci, 1602. 